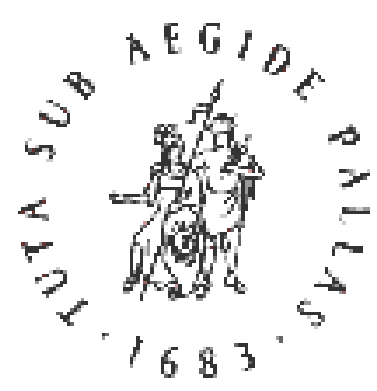

B R I L L

Reproductive Tactics of Male Savanna Baboons

Author(s): Ronald Noë and Albertha A. Sluijter

Reviewed work(s):

Source: Behaviour, Vol. 113, No. 1/2 (May, 1990), pp. 117-170

Published by: BRILL

Stable URL: http://www.jstor.org/stable/4534851

Accessed: 19/10/2012 15:55

Your use of the JSTOR archive indicates your acceptance of the Terms \& Conditions of Use, available at http://www.jstor.org/page/info/about/policies/terms.jsp

JSTOR is a not-for-profit service that helps scholars, researchers, and students discover, use, and build upon a wide range of content in a trusted digital archive. We use information technology and tools to increase productivity and facilitate new forms of scholarship. For more information about JSTOR, please contact support@jstor.org. 
Behaviour 113 (1-2) 1990, E.J. Brill, Leiden

\title{
REPRODUCTIVE TACTICS OF MALE SAVANNA BABOONS
}

\author{
by \\ RONALD NOË and ALBERTHA A. SLUIJTER $\left.{ }^{1}\right)^{2}$ ) \\ (Laboratory of Comparative Physiology, University of Utrecht, The Netherlands) \\ (With 10 Figures) \\ (Acc. 20-IX-1989)
}

\section{Introduction}

The total reproductive effort of a male savanna baboon consists of three distinct components: pre-mating effort, activities that enhance the chances to gain access to receptive females in the future: mating effort, all activities directly aimed at gaining or maintaining access to receptive females and post-mating effort, behaviour that enhances the well-being of offspring. The reproductive success of male savanna baboons (Papio cynocephalus ssp.) has been a subject of several field studies (see Berenstain \& Wade, 1983; Bercovitch, 1986 for recent reviews). The majority of the studies were conducted in East-Africa and involved two subspecies: $P$. c. cynocephalus (the yellow baboon) and $P$. c. anubis (the olive baboon). Most studies dealt with the mating effort of males (Devore, 1965; Saayman, 1971; Hausfater, 1975; Pagker, 1979; HarDing, 1980; Collins, 1981; Bercovitch, 1983, 1986, 1987), or with their post-mating effort, notably paternal care in relation to the phenomenon of agonistic buffering (RANSOM \& RANSOM, 1971; PACKeR, 1980; Busse \& Hamilton, 1981; Busse, 1984; Stein, 1984; Strum, 1984; Pereira, 1989). Smuts (1983, 1985), as an exception, has put emphasis on the pre-mating effort of males.

1) Present address: Ethologie und Wildforschung, Zoologisches Institut, Universität Zürich-Irchel, Winterthurerstrasse 190. CH-8057 Zürich, Switzerland.

$\left.{ }^{2}\right)$ We gratefully acknowledge the permission to carry out research in the Amboseli National Park, Kenya, from the Office of the President, the National Council for Science and Technology, the Ministry of Environment and Natural Resources, and the Warden. We thank J. Altmann, S. A. Altmann and G. Hausfater for their permission to work in the Amboseli Baboon Research Project and the use of data from the long term records. We thank the following people for their support during the field work: M. Buteo, J. Else, R. Mututua, M. Kirega, M. Pereira, A. Samuels and S. Sloane. B. Wechsler kindly helped with the German version of the summary. Financial support was provided by WOTRO grant W84-195. 
In this study we concentrate on the following question: how does a male optimize his reproduction by choosing among several possible behavioural tactics? A male has to make a choice at two different levels. In the first place he has to 'decide' how to distribute his effort over the pre-mating, mating and post-mating tactics. A male that invests in mating further has to opt for one of several methods of gaining access to oestrous females. Some tactics are incompatible with each other. For example, baboons guard and herd females in oestrus during so called 'consorts'. Being in consort, a 'mating tactic', is hard to combine with the protection of an infant, a 'post-mating tactic'. Other tactics can be compatible with each other, like the protection of the mother of potential offspring and the pre-mating effort aimed at increasing the chance of fathering the female's next infant.

Three components of reproductive effort.

\section{The pre-mating component.}

Pre-mating effort directed at a female before her receptive period may manifest itself as frequent affinitive behaviour, close proximity, or support in agonistic conflicts. 'Special relationships' or 'friendships' (SMUTs, 1985) may affect the access to the female in her receptive period in two ways: firstly, through a positive effect on the female's mate choice (SMUTs, 1985), and secondly, through the creation of an asymmetry in conflicts with other males over the female (Maynard Smith \& Parker, 1974: see the experiments of KUMMER and his co-workers with hamadryas baboons (Kummer et al., 1974; Bachmann \& Kummer, 1980). The suggested asymmetry between a consorting male and his challengers may be a pure 'uncorrelated asymmetry' of the owner-rival type, in which case the two explanations for pre-mating effort are disjunct. The asymmetry may also be a 'pay-off asymmetry' (MAYNARD SMITH \& PARKER, 1976) due to the female's preference for the consorting male, in which case the two explanations strongly overlap.

\section{The mating component.}

The result of a male's mating effort is usually measured as his 'mating success' relative to that of other males. Mating success can be measured in two different ways, depending on whether ultimate or proximate questions are emphasized. 
In studies with ultimate interests mating success variant 1 (MS1) has been used: the best possible estimate a field biologists is able to make of a male's lifetime reproductive success without making use of techniques like DNA-fingerprinting, and without observing the male throughout his reproductive career. In the case of baboons MS1 is determined by counting the number of females a male copulated with close to the moment she conceived (see Bercovitch, 1987, for a more detailed discussion of the use of reproductive parameters). MS1 among male baboons has been a main topic of a number of publications, a.o. Hausfater, 1975; PAGKer, 1979; Smuts, 1985; Bercovitch, 1986. The correlation of MS1 with actual reproductive success may be rather weak in several primate species (chimpanzees (Pan troglodytes): Tutin, 1979; rhesus macaques (Macaca mulatta): Curie-Cohen et al., 1983; Stern \& Smith, 1984; longtailed macaques ( $M$. fascicularis): Shively \& SMith, 1985). As far as species with concealed ovulation are concerned (e.g. macaques) the lack of correspondence between MS1 and actual reproductive success is not surprising. In species like baboons and chimpanzees, with very obvious perineal swellings directly coupled to the menstrual cycle, the correspondence may perhaps be better, but will still be far from perfect.

This paper is primarily concerned with the proximate causes of variations in mating success. We are interested in strategic decisions males make on the grounds of information they have at the time the decision is made. We assume that male mating behaviour in general is tuned to optimize reproductive success, but we make no effort to estimate the actual reproductive success. We present data on a second variant of mating success $(M S 2)$ : the success of a male in reaching the goals he apparently strived for. As with MS1 a males performance on MS2 is measured relatively to the other male's in his group. With respect to MS2 it does not matter whether a male gained access to a fertile or an infertile female, as long as he had to put the same amount of effort into gaining access. To give an example: female baboons often go through several menstrual cycles prior to conception (Altmann, 1980). The behaviour of males towards females during menstrual cycles in which no conception takes place is not necessarily different from their behaviour towards females during fertile cycles. In the case of MS1 some qualitative differences are important that can only afterwards be determined by the observer; in the case of MS2 qualitative differences are only important when they are likely to be conceivable by the males. For MS1 those cycles are singled out as being of high quality, in which conception took place, a fact established on the basis of post hoc observations. For MS2 the low 
quality menstrual cycles are singled out on the basis of the level of interest of males. Thus, when a female had several cycles prior to conception, we singled out the first cycle, which is physically different from the other cycles (longer cycle, smaller swelling) and which attracts less interest from the males, as being a 'low quality' cycle. A student of MS1 would classify all cycles but the last as 'low quality' cycles.

\section{The post-mating component.}

Once a male has offspring he has an option to put energy into its wellbeing. This energy can be spent in several ways. He can protect infants against predators and conspecifics (PACKER, 1980; van NOORDWIJK \& van Schaik, 1988), influence their rank (Pereira, 1989), improve their access to resources at the expense of other group members, or improve the well-being of other care-givers: notably the infant's mother.

The expected distribution of mating success over adult males.

The 'priority of access' model (Altmann, 1962), which predicts a strong correlation between a male's agonistic rank and his mating success, has long been the dominant model explaining differential mating success of males in multi-male primate groups. A number of studies on macaques and baboons (reviewed in Berenstain \& WADE, 1983 and Bercovitch, 1986) revealed, however, that the predictive ability of the model is rather poor. A rank order-mating success relation can a priori not be expected when no clear-cut linear rank order can be determined as was the case for a number of studies conducted on two large groups of olive baboons at Gilgil, Kenya (Manzolillo, 1982; Smuts, 1985; Strum, 1982; Nö̈, 1989). It is also not surprising that an agonistic rank order based on dyadic conflicts is not a good predictor of the outcome of the polyadic interactions that often occur around oestrous females. Individual fighting ability, as estimated by agonistic rank, is but one factor that potentially determines a male's mating success. Other factors of potential importance are: (1) age (experience), (2) period of residence (STRUM, 1982), (3) ability to form coalitions (SMUTs, 1985, Nö̈, 1986, 1989, in press; BERCovitch, 1988), (4) natal/immigrant status (PAGKer, 1979) and (5) the affinitive relationships with females (Smuts, 1985). Depending on the composition of the adult male subgroup several factors can be closely related, notably rank, age, period of residence and ability to form coalitions (PAcker, 1979; Strum, 1982; SMuts, 1985; Nö̈, 1989). It is possi- 
ble therefore, that the significance of the correlation between rankorder and mating success depends on the relation between rank order and one or more of the other factors.

The approach taken in this study is to analyse the use of reproductive tactics not per attribute (e.g. rank, residence status), but per individual, each of which represents a combination of attributes. Because of the rather strong correlation between various attributes the males fell into a limited number of classes of similar individuals. The rank orders in the two study groups were stable enough to guarantee that the correlations with rank are not obscured. Decoupling of rank from individuals (cf. HAUSFATER, 1975) would impose the opposite risk: patterns that would be taken for rank effects could, in fact, be attributable to individual idiosyncrasies, or the effect of other attributes closely linked to rank.

\section{Mating tactics.}

The term 'tactic' is used here to describe complex behavioural sequences that are performed to reach certain proximate goals. For example, forming a coalition in order to gain access to an oestrous female is a 'tactic'. 'Strategies' are decision rules that prescribe which action has to be taken, e.g. which tactic has to be used, under certain circumstances. For example: it is a 'strategy' to form coalitions against higher ranking males, but to fight single-handed against lower ranking males. The use of a certain tactic can be observed directly in the field, the use of a certain strategy has to be inferred from a large number of events. (See also Dunbar, 1988 , for a discussion of the use of the terms tactic and strategy).

We use the term 'mating tactic' to refer to the method used by a male to acquire, and keep, consorts. The most obvious method is the use of individual fighting ability, hereafter referred to as the 'solo tactic'.

Several authors (Packer, 1977; Strum, 1982; Smuts, 1985; BerCOVITch, 1986, 1988; Nö̈, 1986, 1989, 1990) have indicated the importance of coalitions in the battle over consorts among male baboons. Generally speaking males often obtain consorts partly or completely due to the effort of other males. Whether the mechanism behind this phenomenon is based on opportunism, reciprocity, or otherwise is discussed elsewhere (NoË, 1989, 1990; see also Bercovitch, 1988). For the purpose of this paper we distinguish one single tactic, the 'combo tactic', to refer to all methods of consort acquisition that depend on the action of other adult males apart from the consorting male.

A considerable number of consorts are started and maintained without 
noticeable opposition from other males (Bercovitch, 1988). This may in theory occur for two reasons. (1) Males concentrate on certain females and thereby build up a strong 'ownership'-asymmetry. The other males in turn become reluctant to compete over those females. Such a show of 'ownership' can only be staged for very few females, therefore such males can be labelled 'specialists'. (2) Males may start consorts when no one else is interested. This can be expected for consorts of low quality and for males with a low rank. We use the label 'avoider' for such males. Specialists should be distinguishable from avoiders, because the former have high quality consorts with relatively few females, while the latter should have low quality consorts with a large number of females. The method used by both types of males in acquiring consorts is indistinguishable, however. Both obtain consorts in a peaceful manner: the 'contest-free tactic' (see Methods-section for operational definitions of the three tactics).

The expected distribution of paternal care.

The expected distribution of paternal care is closely linked to the expected distribution of mating success. When a pure priority-of-access model applies, male baboons will sire most of their infants in the period they occupy a high rank, which for most male baboons is a relatively short period following their immigration (PAGKER, 1979; NoË, 1989). Males are therefore predicted to direct most of their parental effort to those infants that have been sired in that period. This hypothesis is referred to as the 'diagonal hypothesis' after the expected pattern of exceptional values in a matrix of male paternal behaviour towards infants (Fig. 1). When the priority-of-access model does not apply, males are

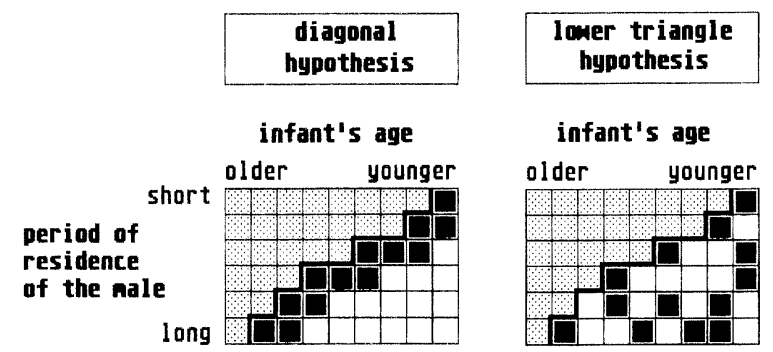

infant conceived before the male's immigration (receives little care).

u infant conceived after the male's immigration, receives high proportion of male's care.

infant conceived after the male's immigration receives relatively little care from male.

Fig. 1. Hypothetical distributions of the care-taking effort of males. 
expected to sire infants over a prolonged period. The only prediction that is made is that males will restrict their paternal effort to infants conceived after their arrival. This hypothesis is called the 'lower triangle hypothesis'. Males do not necessarily distribute their effort equally over all infants conceived after their arrival. In which infants they are interested specifically, is expected to depend on their mating history with the mothers.

SMuts (1985) suggested that males care for infants primarily in order to improve their bond with the mother of the infant. Care for infants would thus be a pre-mating rather than a post-mating tactic. Under that hypothesis males are not expected to discriminate between infants sired before and after their immigration. Pereira (1989) and Walters (cited in Pereira, 1989) reject Smuts' hypothesis. The hypothesis may only apply to newcomers in the period they try to form bonds with the resident females. In the latter form the hypothesis is hard to test, since a comparison between potential offspring and other infants is not feasible in the case of newcomers. The suggested mechanism would nevertheless be plausible, if newcomers put considerable effort into care for infants.

\section{Methods}

Groups.

The data were collected in two groups of yellow baboons ( $P$. c. cynocephalus) in Amboseli National Park, Kenya between December 1, 1981 and December 1, 1982. The groups were usually visited on alternating days. One group, Alto's Group, had been under study from 1971 (Hausfater, 1975; Altmann, 1980). The other group, Hook's Group, had been under study with intervals since 1976, and on a regular basis since 1980. Group sizes and composition are given in Table 1.

TABLE 1. Size and composition of study groups

\begin{tabular}{lccccc}
\hline $\begin{array}{l}\text { Name of } \\
\text { group }\end{array}$ & $\begin{array}{c}\text { Group } \\
\text { total }\end{array}$ & $\begin{array}{c}\text { Minimum and maximum numbers during the study } \\
\text { Mature } \\
\text { immigrant } \\
\text { males }\end{array}$ & $\begin{array}{c}\text { Mature } \\
\text { natal } \\
\text { males }\end{array}$ & $\begin{array}{c}\text { Mature } \\
\text { females }\end{array}$ & $\begin{array}{c}\text { Sex ratio } \\
\text { mature males/ } \\
\text { mature females }\end{array}$ \\
\hline $\begin{array}{l}\text { Hook } \\
\text { Alto }\end{array}$ & $33-41$ & $6-7$ & 0 & $14-16$ & $0.38-0.47$ \\
\hline
\end{tabular}

Codes of the males.

The males have a code which indicates their group ( $\mathrm{H}$ or $\mathrm{A})$, their rank in an overall rank-order for the whole study period, and the residence status (-i for immigrant and - $n$ for natal). The residence status is only indicated when relevant. The names of the males, 
TABLE 2. The mature males of the study groups

\begin{tabular}{|c|c|c|c|c|c|}
\hline Code & Name & Birth & Immigration & Emigration & Remarks \\
\hline \multicolumn{6}{|c|}{ Hook's group } \\
\hline $\mathrm{H} 1-\mathrm{i}$ & Ozzie & 24 Dec 74 & 8 May 82 & & $(=A 9-n)$ \\
\hline $\mathrm{H} 2-\mathrm{i}$ & Leonard & & $19 \mathrm{Feb} 82$ & & \\
\hline H3-i & Styx & & 1 Oct 81 & & \\
\hline H4-i & Kong & & 25 Apr 81 & & \\
\hline H5-i & Stu & $\sim 1969$ & 26 Jun 80 & & (born in Alto) \\
\hline H6-i & Warlock & & 11 Jun 80 & & \\
\hline $\mathrm{H} 7-\mathrm{i}$ & Slik & & $\sim 1 \operatorname{Dec} 77$ & & \\
\hline H8-i? & Harvey & & $<$ Oct 77 & 26 Apr 82 & $(=\mathrm{A} 8-\mathrm{i})$ \\
\hline \multicolumn{6}{|c|}{ Alto's group } \\
\hline A1-i & Nol & & 7 Oct 82 & & \\
\hline A2-i & Kojak & & 4 Oct 80 & & \\
\hline A3-i & Leroy & & 14 Sep 80 & & \\
\hline A4-i & Teta & & 8 May 78 & & \\
\hline A5-i & Omen & & 8 Dec 80 & & \\
\hline A6-i & Kush & & 25 Dec 78 & & \\
\hline A7-i & Aly & & 3 Dec 78 & & \\
\hline A8-i & Harvey & & 22 Jun 82 & 7 Nov 82 & $(=\mathrm{H} 8-\mathrm{i})$ \\
\hline A9-n & Ozzie & $24 \mathrm{Dec} 74$ & & $27 \mathrm{Feb} 82$ & $(=\mathrm{H} 1-\mathrm{i})$ \\
\hline A $10-n$ & Fred & 1 Jan 75 & & & \\
\hline
\end{tabular}

used in other publications on the Amboseli baboons, are given in Table 2. The overall rank order, which also orders males that were not in the group at the same time, serves as a reminder of the relative status of a male. When a male occupied several ranks during the study period he was given an average of these ranks, whereby the periods over which he kept the rank were weighed according to their importance, i.e. number of consorts observed, not according to their length. Thus 'H3-i' was an immigrant in Hook's group, who occupied rank three in the overall rank order. Two males who migrated between Alto's Group and Hook's Group have two different codes. A9-n of Alto's Group became H1-i in Hook's Group and H8-i of Hook's Group became A8-i in Alto's Group. The real rank orders and their changes over time are indicated in Figs 2a and b. These rank orders are based on the dominance relationships in pairs of males. For the dominance criterion used see below.

Age, maturity and residence status.

Males were classified on the basis of age, maturity and residence status. The subjects of this study were the mature males of both groups. The class of mature males includes all adult males and some of the males that were subadult according to the classification given by Altmann et al., 1983. Subadult males were considered to be (sexually) mature after they were observed in consort (definition see below) with a female with a swollen perineal skin. Females were considered mature after menarche. Unless indicated otherwise 'male' means 'mature male' and 'female' means 'mature female'. The residence status of a male is indicated with 'natal' or 'immigrant'. All immigrants were known or estimated to be at least seven years old. In Table 2 the immigration dates of all males and known birth dates are listed. 

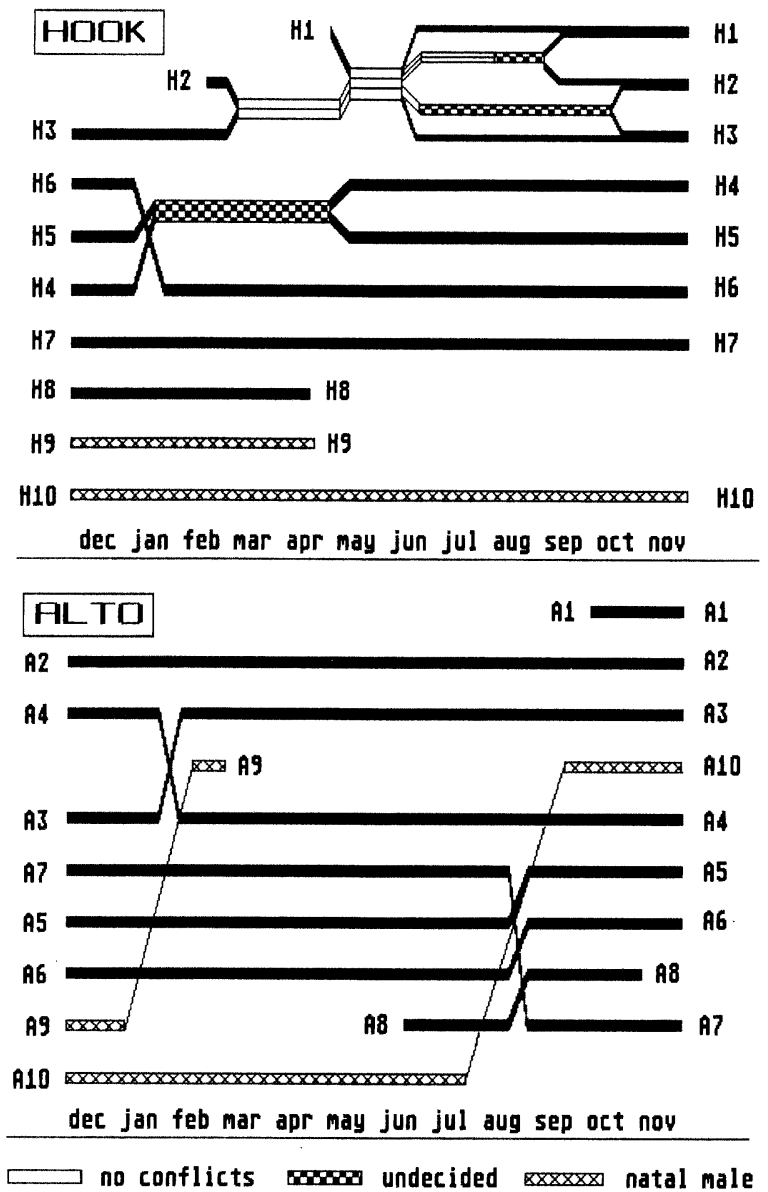

Fig. 2. Rank and rank changes of the mature males over the study period. The rank of a male at any point in time can be found by counting the males present from top to bottom. Two males were considered to have a 'decided' dominance relationship over all periods between two conflicts in which one and the same male had shown submissive behaviour. When no conflicts were seen between two males over a period of at least a month a period of 'no conflicts' is indicated.

\section{Observational methods.}

Both groups were well habituated and could be followed on foot. The data used in this paper were gathered using the ad libitum method and the focal animal method (Altmann, 1974). The group sizes and visibility in Amboseli were such that for highly conspicuous events (consorts, polyadic conflicts and conflicts with vocalizations) the ad libitum observations were virtually focal group samples. Focal animal samples, recorded with the help of a portable electronic event recorder, were 20 minutes in duration and 
TABLE 3. Observation time and number of samples per individual (Amboseli Nat. Park, Kenya: 1 Dec. 81-30 Nov. 82)

\begin{tabular}{lcc}
\hline Code & $\mathrm{N}$ focal samples & $\mathrm{N}$ proximity samples \\
$<2 \mathrm{~m}$ & Observation time in hrs
\end{tabular}

\begin{tabular}{lrrl}
\hline Hook's group & & & \\
H1-i & $58(2)$ & $562(22)$ & 362 \\
H2-i & $77(7)$ & $801(74)$ & 530 \\
H3-i & $98(16)$ & $1024(171)$ & 671 \\
H4-i & $100(7)$ & $1061(74)$ & 671 \\
H5-i & $99(42)$ & $1019(444)$ & 671 \\
H6-i & $101(11)$ & $1050(119)$ & 671 \\
H7-i & $95(10)$ & $985(101)$ & 671 \\
H8-i? & $41(0)$ & $420(0)$ & 268 \\
H9-n & $43(0)$ & $448(0)$ & 298 \\
H10-n & $101(0)$ & $1011(0)$ & 671 \\
& & & \\
Alto's group & & $96(11)$ & 134 \\
A1-i & $9(1)$ & $673(133)$ & 785 \\
A2-i & $65(14)$ & $683(30)$ & 785 \\
A3-i & $67(3)$ & $703(115)$ & 785 \\
A4-i & $67(11)$ & $659(64)$ & 785 \\
A5-i & $65(6)$ & $685(52)$ & 785 \\
A6-i & $67(5)$ & $648(20)$ & 296 \\
A7-i & $67(2)$ & $272(11)$ & 785 \\
A8-i & $27(1)$ & $166(0)$ & 785 \\
A9-n & $16(0)$ & $674(22)$ & 785 \\
A10-n & $66(2)$ & $691(0)$ & 785 \\
A11-n & $67(0)$ & $662(0)$ & \\
A12-n & $69(0)$ &
\end{tabular}

$\mathrm{x}(\mathrm{y}): \mathrm{x}=$ total number of samples; $\mathrm{y}=$ samples 'in consort'.

started at fixed intervals throughout the day. The data were gathered by the two authors: Hook's Group: 73 observations days, 670.5 hours of ad libitum recording. Alto's Group: 85 observation days, 785.5 hours of ad libitum recording. In Table 3 the number of samples per male is given. For some analyses the data were supplemented by data gathered by other observers: R. S. Mututua, A. Samuels and S. A. Sloane.

\section{Dominance criterion.}

We established the formal dominance relationship (de WAAL, 1987) between two animals on the basis of submissive behaviour shown in conflicts that were least likely to be influenced by other group members. The conflicts used were dyadic conflicts and the starting dyads of polyadic conflicts. The data on agonistic conflicts in Alto's Group gathered over a three months period were used for an analysis of the degree of correspondence of 22 agonistic behavioural elements as far as the direction of performance within pairs of animals was concerned. Per element a matrix of animal pairs with the main direction of 
occurrence was constructed. The number of animal pairs in which both elements had the same main direction, expressed as a proportion of all pairs of animals in which both elements were observed, was used as a parameter for the agreement between the two elements (see similar methods in Rowell, 1966; de WAAL, 1977; Nö̈ et al., 1980). Six behavioural elements were found to be highly consistent which each other: 'lean-aside'/ 'flinch', 'jump back', 'tail-up', 'grimace', 'gecker' and 'scream' (Nö̈, unpubl. data). In the 15 pairs of elements both elements were observed in 26 to 193 animal-pairs (mean 74.5). The same animal was submissive according to both elements in $93 \%$ to $100 \%$ of the cases. Aggressive elements showed a much lower consistency, which makes them unsuitable as criteria for formal dominance. Therefore we considered an animal to be the subordinate when it showed at least one of the six 'submissive' elements in a conflict while its opponent did not.

\section{Oestrous cycles.}

Female sexual states were monitored each observation day. The colour of the paracallosal skin, the size of the perineal swelling, the onset of deturgescence of the swelling and menstrual bleeding were scored. The day of deturgescence is called D0, the other days of the cycle are counted backwards (D-1, D-2 etc.) till the previous menstruation, and forwards $(\mathrm{D}+1, \mathrm{D}+2$ etc. $)$ till the next menstruation. Under the assumption that cycles of females in the wild do not differ dramatically from cycles of females held in a laboratory, ovulation most likely takes place on D-3 (Hendrickx \& Kraemer, 1969) or D-2 (ShaikH et al., 1982). There may be a difference of one day between researchers, due to differences in the definition of D0.

\section{Consorts.}

A consort is defined as: a period of persistent close proximity and attuned locomotion of an adult male and a female with a swollen perineal skin, lasting longer than 30 minutes. Close proximity was subjectively established, relative to the distance between the female and other adult males. Consort pairs at the periphery of the group can be several meters apart. Undisturbed copulations during consorts shorter than 30 minutes were unlikely.

\section{Parameters of mating success.}

A number of parameters of mating success can be used; the choice mainly depends on the goal and taste of the researcher (see Bercovitch, 1987, for a discussion). The most frequently used are: number of copulations (with refinements like copulations with intromission, copulations with ejaculation), the number of consorts, and the total time in consort.

In this paper the number of consorts will be used as the basic parameter of mating success. This choice is made for the following reasons:

1. Consorts are used instead of copulations, because:

A. In contrast to some macaque species (van NoordwiJK, 1985; HuFFMAN, 1987, and references therein) a consorting baboon male has exclusive access to his female. Another male has to end the consort first and form a new consort himself in order to be able to copulate with the female. A parameter based on consorts is therefore also an indication of a male's ability to exclude others, and of the time he spends on reproductive activity. We do not agree with HAUSFATER's (1975) observation that copulations of interest to the present topic, i.e. copulations that are primarily performed for the sake of reproduction, often occur outside consorts. 
B. Copulations are of short duration compared to consorts and can therefore easily be missed. Under the circumstances of the present study a consort could hardly pass unnoticed. Bias in the data may result from a difference between low and high ranking males in the tendency to copulate in concealment (Loy, 1971; Drickamer, 1974). The number of copulations can therefore only be used in combination with the focal animal technique, which would reduce the data-set considerably.

2. The number of consorts instead of the total duration of time in consort, because:

A. The number of copulations is not proportional to the length of the consort. Typically males copulate once or twice at the start of a consort: other copulations may follow at irregular intervals. Therefore total consort duration is not a good parameter. For example, three consorts of one hour each with three different females are not equivalent to one consort of three hours with one female.

B. The time in consort not observed before the daily observations started and after they stopped, causes bias in the data. Especially the early morning consorts are not distributed equally over the males (see Results-section). The resulting bias is more severe for the parameter 'duration' than for the parameter 'frequency'. A considerable part of a consorts' duration may not be observed, while it is unlikely that consorts as entities have often been missed. Consort activity during the night could not be observed, but mating activity at night was expected to be low (see SMuts, 1985 , and below). 'Duration' will, however, be discussed as one of the qualitative aspects of consorts.

The arbitrariness of our choice of a parameter of mating success, or any other choice, must be stressed. No single parameter based on field observations, can reflect the multidimensional probability that one would like to estimate.

\section{Operational definitions of mating tactics.}

Solo tactic: the male obtained the consort after an agonistic conflict with a consorting male in which no other male directed aggression towards the consorting male and/or defended the consort against one or more challengers in an agonistic confict in which no other male directed aggression to a challenger.

Combo tactic: the male obtained or defended the consort with the help of one or more other adult males, that is: one or more other adult males directed aggression against the previous consorting male at a take-over, or against a challenger during the consort. A combo playing male was usually, but not necessarily, involved in the conflict himself. When both the solo and the combo tactic were played for a single consort, the qualification combo was given, when the consort was acquired using that tactic, or when at least half of the consort period followed the conflict in which the combo tactic occurred.

Contest-free tactic: a male was said to have used the contest-free tactic when he obtained and maintained his consort without being involved in a conflict with another adult male, except for conflicts that clearly had other immediate causes. An agonistic conflict in this context is any interaction between two individuals in which at least one agonistic behavioural element (threat, attack or submission) was shown.

\section{Methods of analysis.}

The differentiation between males in the use of various strategies is partly reflected in differences in the distribution of social behaviour over their group members. To reveal these differences we analysed the adjusted residuals of contingency tables of the males against group members (EveritT, 1977). The technique is used here as a descriptive tool. 
TABLE 4. Time spent socially, in consort or alone

a. Scores per 500 samples

\begin{tabular}{|c|c|c|c|c|c|c|c|c|c|}
\hline & & Hook & & & & & Alto & & \\
\hline & Social & Consort & Alone & Total & & Social & Consort & Alone & Total \\
\hline $\mathrm{H} 1$ & 40.0 & 19.6 & 440.4 & 500 & $\mathrm{~A} 1$ & 57.3 & 57.3 & 385.4 & 500 \\
\hline $\mathrm{H} 2$ & 72.4 & 46.2 & 381.4 & 500 & A2 & 65.4 & 98.8 & 335.8 & 500 \\
\hline H3 & 101.1 & 83.5 & 315.4 & 500 & A3 & 103.2 & 22.0 & 374.8 & 500 \\
\hline $\mathrm{H} 4$ & 169.2 & 34.9 & 295.9 & 500 & A4 & 143.7 & 81.8 & 274.5 & 500 \\
\hline H5 & 128.6 & 217.9 & 153.6 & 500 & A5 & 152.5 & 48.6 & 298.9 & 500 \\
\hline H6 & 158.1 & 56.7 & 285.2 & 500 & A6 & 195.7 & 31.5 & 272.7 & 500 \\
\hline $\mathrm{H} 7$ & 195.9 & 51.3 & 252.8 & 500 & A7 & 158.9 & 15.4 & 325.6 & 500 \\
\hline H8 & 108.3 & 0.0 & 391.7 & 500 & A8 & 86.4 & 20.2 & 393.4 & 500 \\
\hline & & & & & $\mathrm{A} 10$ & 153.6 & 16.3 & 330.1 & 500 \\
\hline Tot. & 973.6 & 509.9 & 2516.4 & 4000 & Tot. & 1116.7 & 391.9 & 2991.4 & 4500 \\
\hline
\end{tabular}

b. Adjusted residuals

\begin{tabular}{lccccccc}
\hline & Social & $\begin{array}{c}\text { Hook } \\
\text { Consort }\end{array}$ & Alone & & Social & $\begin{array}{c}\text { Alto } \\
\text { Consort }\end{array}$ & Alone \\
\hline H1 & -- & -- & ++ & A1 & -- & - & ++ \\
H2 & -- & - & ++ & A2 & -- & ++ & \\
H3 & - & + & & A3 & - & -- & ++ \\
H4 & ++ & -- & & A4 & + & ++ & -- \\
H5 & & ++ & -- & A5 & ++ & & -- \\
H6 & ++ & & - & A6 & ++ & - & -- \\
H7 & ++ & & -- & A7 & ++ & -- & ++ \\
H8 & & -- & ++ & A8 & -- & -- & +- \\
& & & & A10 & ++ & -- & \\
df $=14$, Dunn Sidak & z $=2.90$. & & df $=18$, Dunn-Sidak z $=2.97$. & \\
\hline
\end{tabular}

(On the basis of 500 proximity samples, see text for explanation). Social: one or more group members $<2 \mathrm{~m}$ of focal male. Consort: focal male in consort with oestrous female. Non-social: neither of the above. Shown are Adjusted Residuals: ++/--: significant according to the Dunn-Sidak criterion. +/-: significant according to the Everitt criterion $(\mathrm{z}=1.96)$.

One has to be very careful when indicating the statistical significance of values in a large table of group members of class A against members of class B for two reasons: firstly, the data suffer from interdependencies, and secondly, because of the sheer size of some tables, significant values are likely to show up by chance alone. Therefore two significance levels are indicated: one is the $5 \%$ standard normal deviate $\mathrm{z}(=1.96)$ as proposed by EVERITT (1977), the other is the standard normal deviate $\mathrm{z}$ corresponding to an 
experimentwise error rate of $5 \%$ calculated by use of the Dunn-Sidak method (SoKAL \& RoHLF, 1981). According to the latter method a significance level $\alpha^{\prime}$ is used per cell such that the value of $\alpha$ for the total table does not exceed the chosen significance level of 0.05 . The formula used is: $\alpha^{\prime}=1-(1-\alpha)^{1 / k}$ ( $\mathrm{k}$ is the number of degrees of freedom). Hereafter we will refer to these criteria as the Everitt criterion, respectively the Dunn-Sidak criterion. The Dunn-Sidak criterion is always more strict than the Everitt criterion and the exceptionality of values indicated by using the criterion can be considered meaningful. The Everitt criterion is merely used to enhance the descriptive power of the analyses.

Note that a significant value indicated with this method, e.g. a proximity score between male $\mathrm{x}$ and age-sex class $\mathrm{A}$, means that $\mathrm{x}$ is relatively often in the vicinity of members of class A. One has to consider male x's total (absolute) proximity score, given in Table 4, to appreciate the frequency of proximity to class A during his total activity.

There is another type of dependency in the proximity-data, inherent to the method of data gathering. The proximity to neighbours was noted in 11 point-samples taken two minutes apart in the 20-minute focal samples. In a moving group the proximity samples of one focal sample are fairly independent of each other. In a steady group, or during a consort, all 11 samples are linked to each other. To eliminate this effect only one proximity sample per focal sample should be used. On the other hand, by taking 11 proximity samples per focal sample emphasis is laid on individuals in close proximity for some length of time, which mostly occurs when the animals are resting or feeding. Proximity while the group is stationary is likely to be less casual than proximity in a moving group.

The number of proximity samples for a male present during the whole study was on average 1025 in Hook's Group and 675 in Alto's Group. Chosen is a uniform score representing 500 proximity samples per male in both groups. Thus statistical tests were conducted on deflated data. The data are corrected for absence and, where appropriate, for time-in-consort. Correction is always done for the absence/time-in-consort of the focal male and all of his group members. The scores therefore reflect a situation in which all individuals were present (and not in consort) during the whole study. This means that the data for males immigrated during the study and infants born during the study are inflated. In other words: the score of an infant born three months before the end of the study is the score of an infant of less than three months old, but present during a whole year.

\section{Results}

1. The distribution of effort over the pre-mating, mating and post-mating tactics.

\subsection{Time spent socially, in consort or alone.}

The proximity-samples were divided in three categories (Table 4):

1. Social: samples in which the focal male had at least one neighbour within two meters.

2. Consort: samples in which the focal male was in consort (regardless whether the consort female or any other group member was within 2 meters).

3. Alone: samples in which the focal male was not in consort and had no neighbours within 2 meters. 
Frequently alone were the recent immigrants (H1, H2, A1, A8), H8-i (who became A8-i) short before his emigration, and A3-i, the most peripheral of all longterm residents. All middle and low ranking longterm residents were relatively social, except $\mathrm{H} 5$-i who devoted most time of all males in the study to the consorting of oestrous females. There were two distinct types of males that spent much time, relatively speaking, to consort-activity: (1) relatively non-social (but not peripheral) highranking males: $\mathrm{H} 3-\mathrm{i}$ and $\mathrm{A} 2-\mathrm{i}$, both of whom were $\alpha$-males at least part of the study and (2) the highest ranking individuals among the longterm residents that relatively frequently played the 'combo' tactic: $\mathrm{H} 5-\mathrm{i}$ and A4-i. The latter two males were also fairly social.

Conclusion 1.1: After immigration males are peripheral, in a second phase high ranking immigrants devote much time to the consorting of oestrous females, after which follows a long phase with more social contact. Some males in the latter phase still devote a considerable amount of time to consort-activity.

\subsection{The distribution of social time over the major age-sex classes.}

Table 5 gives the distribution of social time, measured as proximity within 2 meters, over the major age-sex classes. The older immature males (the 'subadults' in the Table) in Alto's Group were born before any of the immigrants present arrived in the group. In Hook's Group there were no such immature males. The only mature male who had frequent contact with the older immatures in Alto's Group was natal male A10. A10 was only eight months older than the oldest immature male. The males who were relatively often in proximity with other adult males were the 'non-social' males (see Table 4 under 'alone'), but the lack of contact with females and immatures, rather than a bond with other adult males, is characteristic for these males. In both groups the males that most often had juveniles and infants in their vicinity were longterm residents. A5 ranked among the longterm residents (A4, A6 and A7) and was probably of comparable age too, but had immigrated two years later (in the same period as A2 and A3). A5 therefore had fewer potential offspring in the group, which explains his interest in females rather than in juveniles. Females were also relatively often the neighbours of some of the higher ranking males with periods of residence of short $(\mathrm{H} 1, \mathrm{H} 2)$ or medium length (A2, H4). 
TABLE 5. Contribution of the various age-sex classes to the score of 'social' proximity samples

\begin{tabular}{|c|c|c|c|c|c|c|c|c|}
\hline & & Hook & & & & A & lto & \\
\hline & $\begin{array}{l}\text { Adult } \\
\text { males }\end{array}$ & $\begin{array}{c}\text { Adult } \\
\text { females }\end{array}$ & Juveniles & & $\begin{array}{l}\text { Adult } \\
\text { males }\end{array}$ & $\begin{array}{c}\text { Adult } \\
\text { females }\end{array}$ & $\begin{array}{c}\text { Subad. } \\
\text { males }\end{array}$ & Juveniles \\
\hline $\mathrm{H} 1$ & & ++ & -- & $\mathrm{A} 1$ & ++ & & & -- \\
\hline $\mathrm{H} 2$ & + & ++ & -- & A2 & & ++ & & -- \\
\hline $\mathrm{H} 3$ & & & & A3 & ++ & & & -- \\
\hline $\mathrm{H} 4$ & -- & ++ & - & A 4 & -- & -- & ++ & \\
\hline H5 & & - & + & A5 & & + & - & \\
\hline $\mathrm{H} 6$ & & - & + & A6 & -- & & & ++ \\
\hline $\mathrm{H} 7$ & & -- & ++ & A7 7 & - & & & + \\
\hline H8 & ++ & & -- & $\begin{array}{l}\text { A8 } \\
\text { A10 }\end{array}$ & ++ & - & ++ & -- \\
\hline $\mathrm{df}=$ & Dunn & $\mathrm{k} z=$ & & $\mathrm{df}=24$ & unn-Si & $z=3.06$ & & \\
\hline
\end{tabular}

(Samples with at least one group member $<2 \mathrm{~m}$ as given in the column 'Social' in Table 4). Shown are Adjusted Residuals: ++/--: significant according to the Dunn-Sidak criterion. +/-: significant according to the Everitt criterion $(z=1.96)$. Adult males: born before 1976 (at least 6 years old). Subadult males: born in 1976-77 (not present in Hook's group). Adult females: menarche before or during the study. Juveniles: all individuals born after 1977.

Conclusion 1.2: Longterm residents have infants and juveniles relatively often as neighbours. The scarce neighbours of peripheral males, which were mostly males short before or after a migration, were other adult males in most cases. Some higher ranking males had adult females in their vicinity relatively often.

\subsection{The social interaction with juveniles and infants.}

\subsubsection{Proximity.}

We used proximity $(<2 \mathrm{~m})$ during the focal samples in which the male was not in consort as a parameter of social contact between individual males and immatures. The data on all immatures born less than three years before the start of the study have been used. (Infant 1 in Hook's Group might have been slightly older, his birth date was uncertain.) The relative frequency in which male-infant pairs were neighbours is indicated by the adjusted residuals of the contingency tables (Fig. 3). 

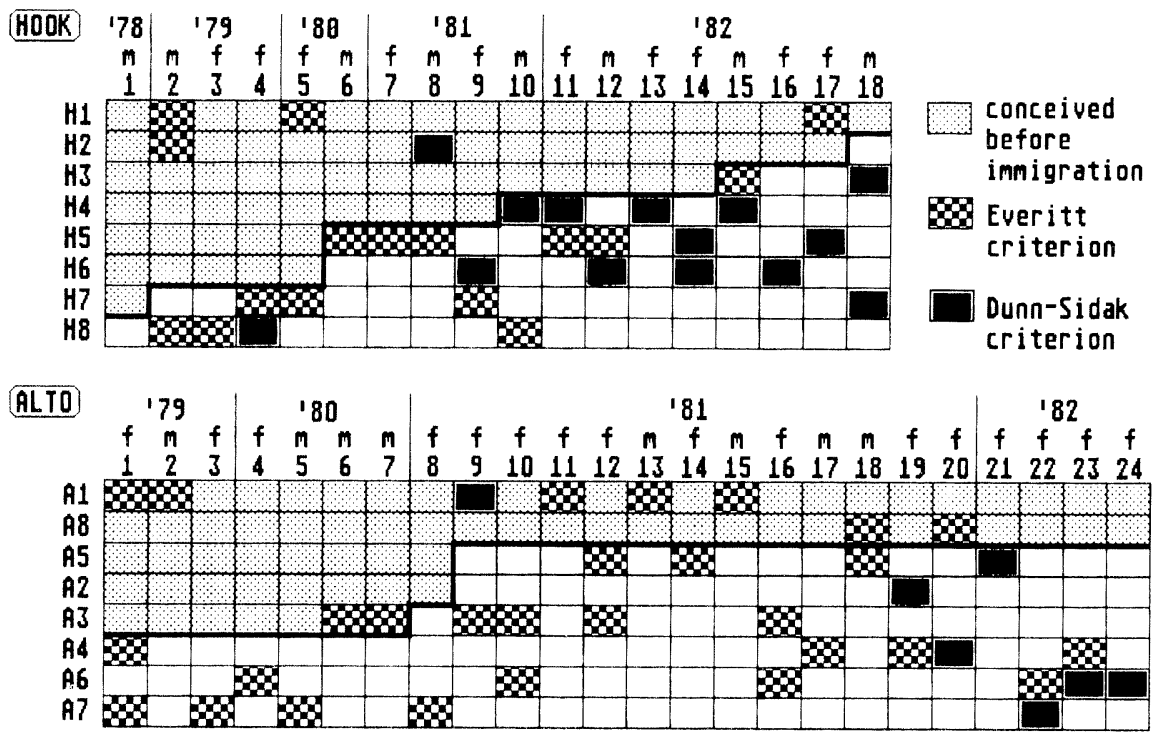

Fig. 3. The proximity between males and immatures. Indicated are the adjusted residuals of a contingency table of proximity scores $<2 \mathrm{~m}$. gathered during the focal male samples. Upper left part of each matrix: immatures conceived before the male immigrated. The immatures are ordered from old to young (their year of birth is indicated): $f=$ female; $\mathrm{m}=$ male. The immigrant males are ordered in reverse order of immigration, hence a deviation with the order as given in other graphs and tables for Alto's Group. Statistics for Hook's Group: $\mathrm{df}=119$. Dunn-Sidak $\mathrm{z}=3.5$; Alto's Group: $\mathrm{df}=184$. Dunn-Sidak $\mathrm{z}=4.65$.

Most infants that were relatively often in the vicinity of a male were conceived after the arrival of that male. For most males no relation between the date of arrival and the birth-dates of infants, other than the distinction before/after immigration, could be recognized. The pattern found is the pattern predicted by the 'lower triangle' hypothesis, rather than the 'diagonal hypothesis' (see Fig. 1). All males seemed to favour the younger infants.

The data on male H4-i, as an exception, fitted the pattern expected according to the 'diagonal hypothesis'. H4 caused several abortions shortly after his arrival (Pereira, 1983). He was $\alpha$-male from his immigration till $\mathrm{H} 3$ arrived five months later, where after he dropped to rank five, before climbing up again. H4 was very interested in four of the six infants conceived in his $\alpha$-period. He spent much time herding their mothers, forming a temporary harem reminiscent of hamadryas 
baboons. It is tempting to think that this male judged other males' intentions by his own.

Some significant scores were found for infants conceived before a male's arrival. In most cases these concern newcomers with no infants conceived after their immigration and with very low scores for proximity with juveniles and infants in general (cf. Tables 4 and 5). Two infants that were found in the proximity of male A3 relatively often, were conceived before his arrival, but born after his arrival. No strong conclusions about the mechanism of recognition of (potential) offspring can be drawn, however, as A3's scores were low in general and none were significant according to the Dunn-Sidak criterion.

Conclusion 1.3.1.: Males restrict their contacts with immatures to individuals conceived after their arrival. Males in general did not restrict their contacts to infants born shortly after their arrival, the period in which most males hold a high rank, although one male showed such behaviour. All males seemed to have some preference for younger over older infants.

\subsubsection{Agonistic support.}

Proximity to an adult male may give protection, or at least easy access to protection, to smaller individuals. Males can also guard and protect infants when they are further away than the two meters reflected in the parameter 'proximity'. Males may protect infants against predators, as well as against group members. The latter kind of protection can also be measured directly as interference by adult males in ongoing agonistic conflicts to the advantage of the infant.

We avoid the assumption of purposiveness suggested by terms like "support" or "interference on behalf of". Our feeling is nevertheless that in the present case, in contrast to interferences among adult males, such a purpose of the interferences can safely be assumed. It can be argued that the close proximity of males to young infants as shown in section 1.3.1. does not reflect paternal effort towards infants, but rather an interest in these infants as 'tools' used in conflicts. (Agonistic buffering hypothesis, Deag \& Crook, 1971: for a review of such male-infant interactions see STrum, 1984.) Popp (1978) argued that males using infants were most likely not the fathers, but Hamilton \& Busse (1981, see also Busse, 1984) found the opposite. Agonistic support for infants in conflicts of the infants with other group members can be seen as a 
direct paternal effort, however, even if the proximate interest of the males would be to protect the 'tools' they need in conflicts. Note that 'paternal effort' here is used for efforts of males that benefit their potential infants, not necessarily their real infants.

The data on interferences to the advantage of infants could not be analysed in the same way as the data on male-infant proximity, because the matrices were less well filled. We therefore reverted to a rather crude analysis. We counted how many infants and juveniles once or more received 'support' in a conflict and how many never received such support. The infants and juveniles were then divided in two classes: conceived before the immigration of the interfering male and conceived after his immigration. This yields $2 \times 2$ contingency tables as shown in Table $6 \mathrm{a}$. The statistical analysis of these tables should be viewed with caution, as the data are highly dependent. We nevertheless consider the results to be meaningful, because the result of the two groups are in agreement with each other and these data are in agreement with the findings on proximity given above.

The data are not corrected for absence, neither of males nor infants. No correction for the absence of infants lowers the chance of acceptance of the alternative hypothesis. Most infants that were not present over the whole period and therefore could be 'supported' over only a short time, were infants born during the study. These very young infants, who were hardly ever involved in conflicts directly, fell in the post-immigration category for most males. The lack of correction for absence of the adult males could have more serious effects. Therefore we did the same analysis without the males that were partly absent. The results are shown in Table 6b. Our results are in agreement with Pereira's (1989) earlier study on the same groups.

Conclusion 1.3.2.: Males regularly support infants that are born after their immigration when these infants have conflicts with group members.

\subsection{The social interaction with adult females.}

\subsubsection{Proximity.}

It is assumed here that the interest of a male for particular females is reflected in the frequency in which the male is in the females' vicinity. The assumption on the meaning of frequent proximity given above implies some more specific assumptions. Firstly, it is assumed that males 
TABLE 6. Interferences in conflicts to the advantages of infants conceived before versus after the immigration

a. All males

\begin{tabular}{|c|c|c|c|c|}
\hline \multirow{5}{*}{$\begin{array}{l}\text { Male never supports immature } \\
\text { Male supports at least once }\end{array}$} & \multicolumn{2}{|c|}{$\begin{array}{l}\text { Hook's group } \\
\text { Conception }\end{array}$} & \multicolumn{2}{|c|}{$\begin{array}{l}\text { Alto's group } \\
\text { Conception }\end{array}$} \\
\hline & $\begin{array}{l}\text { Before } \\
\text { imn }\end{array}$ & $\begin{array}{l}\text { After } \\
\text { lon }\end{array}$ & $\begin{array}{l}\text { Before } \\
\text { imr }\end{array}$ & $\begin{array}{l}\text { After } \\
\text { ion }\end{array}$ \\
\hline & 61 & 58 & 66 & 73 \\
\hline & 8 & 25 & 1 & 35 \\
\hline & \multicolumn{2}{|c|}{$\chi^{2}=6.56, p=0.005$} & \multicolumn{2}{|c|}{$\chi^{2}=22.33, p \ll 0.001$} \\
\hline
\end{tabular}

Test: $\chi^{2}$ with continuity correction, one-tailed. $\mathrm{H}_{0}$ : Both groups of immatures are supported equally often. $\mathrm{H}_{1}$ : males only support infants conceived after their immigration.

b. Males present during the whole study only

\begin{tabular}{lcccc}
\hline & \multicolumn{2}{c}{$\begin{array}{c}\text { Hook's group } \\
\text { Conception } \\
\text { Before After } \\
\text { immigration }\end{array}$} & \multicolumn{2}{c}{$\begin{array}{c}\text { Alto's group } \\
\text { Conception } \\
\text { Before After } \\
\text { immigration }\end{array}$} \\
\hline Male never supports immature & 27 & 36 & 44 & 73 \\
Male supports at least once & 7 & 25 & 1 & 35 \\
& $\chi^{2}=3.20, \mathrm{p}=0.037$ & $\chi^{2}=14.45, \mathrm{p} \ll 0.001$ \\
\hline
\end{tabular}

are usually not in the proximity of females with hostile intentions. The low frequency of male-female agonistic interactions makes it unlikely that such intentions are an important cause of high frequencies of malefemale proximity. Secondly, it is assumed that males and females are not attracted by the same stimuli, other than the female's infant. Attraction to resources like food are not likely to cause a non-random pattern in the proximity frequencies. Thirdly, it is assumed that male-female proximity is not entirely due to female choice. In short, a departure from a random distribution of proximity scores between males and females is expected to be partly due to male choice, but also expected to show considerable 'noise'. A male and a female may exceptionally often be near each other for a number of reasons, e.g. because they are 'friends' (SMUTs, 1985), because the female is the mother of a potential infant of the male, or because the female is a regular consort-partner of the male.

On the basis of the analysis of the proximity data we tried to answer the following question: in which class of females are the males interested: females during their menstrual cycles, females with small infants, or 
females belonging to neither category. We are mainly interested in the bond between males and females when both were not in consort. The data have therefore been corrected for absence as well as time-in-consort. Two different types of analysis have been conducted, one on the basis of differences in proximity to different individual females, the other on the basis of proximity to females in different reproductive states.

For the first analysis the females have been cast into the categories: 'consort-female vs non-consort-female, respectively mother vs nonmother. Each individual female was assigned to one of the two categories and data on proximity with her over the whole study period were used. The results of the first analysis are given in Table 7, together with the definitions used for each category.

TABLE 7. Proximity to adult females under exclusion of consortships

\begin{tabular}{lcc}
\hline Male & $\begin{array}{c}\text { Consorted versus } \\
\text { unconsorted females }\end{array}$ & $\begin{array}{c}\text { Mothers versus } \\
\text { non-mothers }\end{array}$ \\
\hline
\end{tabular}

Hook's group

$\mathrm{H} 1$

$\mathrm{H} 2$

$\mathrm{H} 3$

H4

H5

H6

H7

H8

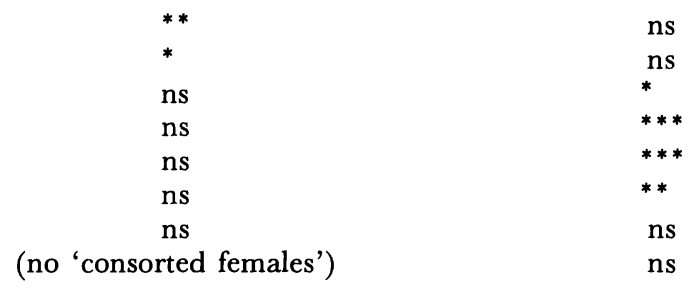

Alto's group

A1

A2

A3

A4

A5

A6

A7

A 8

A10
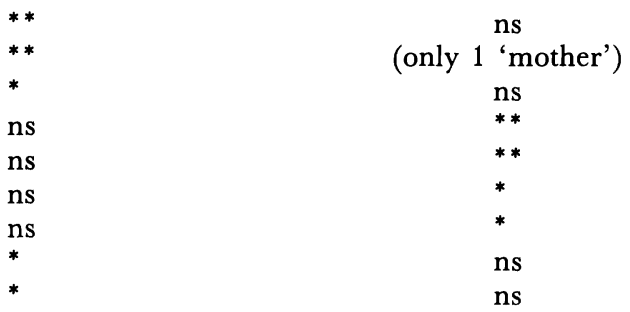

Mann-Whitney U-test, one-tailed. $\mathrm{H}_{0}$ : both categories do not differ. $\mathrm{H}_{1}$ : the males are more often in the proximity of consorted females, respectively mothers. ${ }^{*}: \mathrm{p} \leq 0.05,{ }^{* *}$ : $\mathrm{p} \leq 0.01,{ }^{* * *}: \mathrm{p} \leq 0.001$.

The females have been classified according to the following categories: Consorted female: a female with which a male was seen in consort during the study. Unconsorted female: a female not seen in consort with the male. Mother: mother of an infant with whom the male was in proximity significantly often according to the Everitt criterion (see fig. 3). Non-mother: the female did not have an infant that was often in the proximity of the male. 
In the second analysis the data were cast into four categories: 'cycling', 'mother', 'cycling mother' and 'neither cycling nor mother' and lumped per category for all females. A female for this analysis is a 'mother', if she had a living infant of less than two years of age. Note that 'cycling mothers' never have very young infants, as a result of the length of the postpartum amenorrhea (on average 12 months in Alto's Group, Altmann, 1980). For some high ranking females in Hook's Group, however, this amenorrhea was considerably shorter during the study period. A 'cycling mother' thus has no potential infant of a newcomer, but may

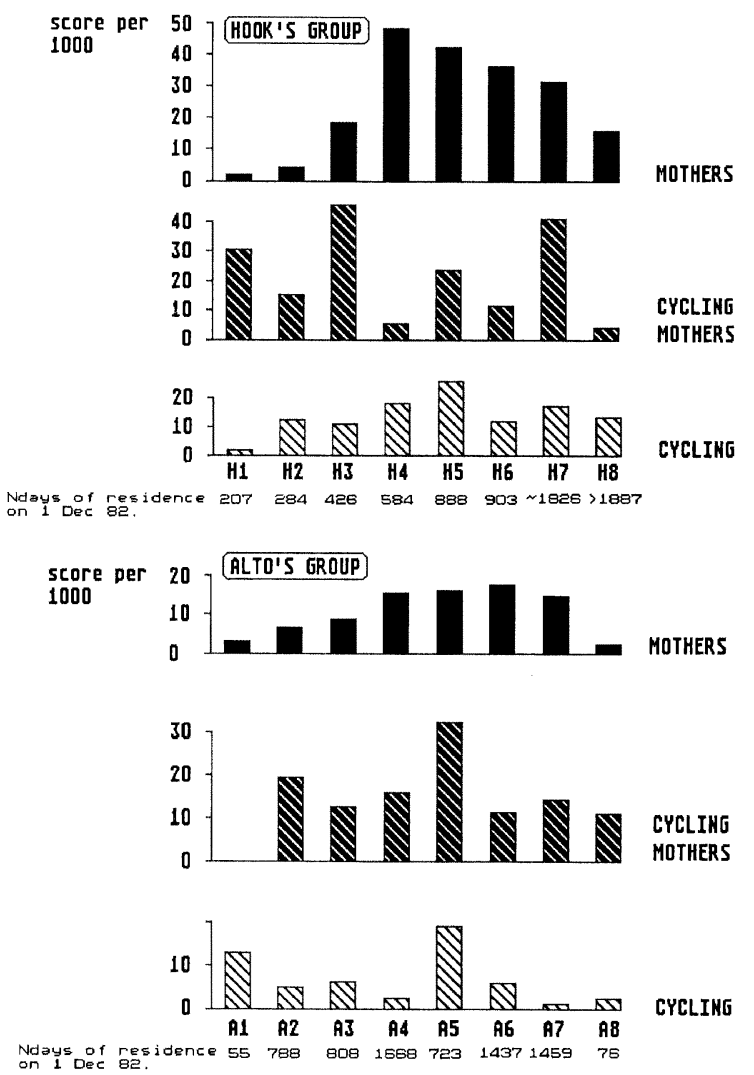

Fig. 4. Estimate of the relative time spent in the proximity of three classes of females. The graphs reflect the scores for proximity between males and females over the focal male samples in which both were present and neither was in consort. Apart from these corrections the data have been corrected for the difference in availability of females belonging to the three different classes. The graphs reflect the proximity scores, as if proximity were a result of the choice of the males among three different classes with an equal number of members. 


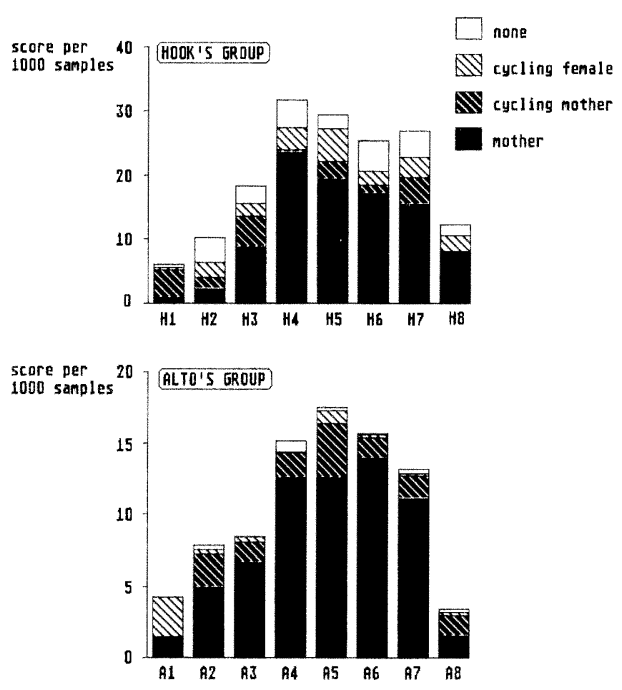

Fig. 5. Estimate of the absolute time spent in the proximity of four classes of females. The graphs reflect the scores for proximity between males and females over the focal male samples in which both were present and neither was in consort. The graphs for the two groups can be compared directly; note the difference in scale.

have a potential infant of an older resident. The interpretation of the frequencies found in the category 'cycling mother' are therefore dependent on the period of residence of the male concerned.

The results of the second analysis are given in the Figs 4 and 5. In Fig. 4 the preference of the males is highlighted, not confounded by differences in the availability of females in the various categories. The following question is answered: given that there are an equal number of females in all categories, which category would attract a male most? The data are corrected in such a way that the score given for each male per category is the score he would have obtained if his maximum potential score for that category would have been 1000. (If all females belonging to the category would have been within 2 meters during all proximity samples of the male, the score would have been 1000.) This correction makes it possible to compare directly between categories and between groups.

Fig. 5 indicates how the males actually divided their time between the several categories of females. Here we only corrected the data in such a way that the total potential score, for all females taken together, was the same for all males in the two groups. The graphs thus reflect the availability of each category of females as well as the male's interest in 
these categories. The relative availability was not the same between groups, neither within groups for males that were not present over the same period.

Conclusion 1.4.1.: Proximity to 'mothers' is strongly dependent on the period of residence (and the rank) of a male. The pattern is, as can be expected, parallel to the pattern of male-immature proximity. The proximity to 'cycling' females (including 'cycling mothers') varies among males, but does not show a clear pattern. If we assume, however, that longterm residents sit with 'cycling mothers', because they are the mothers of their potential infants, and newcomers because they are in the first place sexually attracted to these females, then a pattern emerges which shows that recent immigrants are relatively most interested in 'cycling' females in general. It can only be safely concluded, however, that recent immigrants sit often with 'cycling' females as compared to their own score for proximity with 'mothers'. This is mainly due to the low scores of these males for proximity to 'mothers'.

\subsubsection{Agonistic support.}

As in the case of infants the protection of females can be observed directly as interferences in conflicts to the advantage of the females. Again we tried to analyse whether the interferences were exceptionally often to the advantage of the females the males consorted with and/or the mothers of their potential offspring. In comparison to the proximity-tables the tables of interference-behaviour are less well filled, although all ad libitum data were used, thus including the (few) interferences of males in conflicts of females they were in consort with. In both groups most interferences were done by the longterm residents. An analysis parallel to the first analysis done for the proximity data was conducted only for those males that had interfered at least 10 times to the advantage of females. The results of this analysis are shown in Table 8 . The results are in agreement with the data on proximity.

Conclusion 1.4.3.: Males that frequently interfere in agonistic conflicts to the advantage of females do so mainly to the advantage of the mothers of their potential offspring. 
TABLE 8. Agonistic interference to the advantage of adult females

\begin{tabular}{lcc}
\hline Male & $\begin{array}{c}\text { Consorted versus } \\
\text { unconsorted females }\end{array}$ & $\begin{array}{c}\text { Mothers versus } \\
\text { non-mothers }\end{array}$ \\
\hline Hook's group & $n$ & $* *$ \\
H4 & ns & ns \\
H5 & ns & $* *$ \\
H6 & ns & \\
H7 & $*$ & \\
Alto's group & & $* *$ \\
A4 & ns & ns $(<0.10)$ \\
A5 & ns
\end{tabular}

Mann-Whitney U-test, one-tailed. $\mathrm{H}_{0}$ : both categories do not differ. $\mathrm{H}_{1}$ : the males interfere more to the advantage of consorted females, respectively mothers. ${ }^{*}: p \leq 0.05$, ${ }^{* *}: \mathrm{p} \leq 0.01,{ }^{* * *}: \mathrm{p} \leq 0.001$.

Females classified as in Table 7. For the males in this table the 'mothers' are all mothers of 'potential infants', i.e. infants conceived after the male's arrival. Data are given only for males that interfered to the advantage of one of the adult females at least 10 times (range 10 to 34 times).

\section{Conclusion Section 1.}

The pattern of allocation of effort over the pre-mating, mating and postmating tactics was as follows: males that were high ranking, but not newcomers, and some successful middle ranking males obtained most consorts and thus devoted a relatively large proportion of their time to the 'mating' tactic. These males were relatively often near females showing menstrual cycles during their time spent socially but not in consort. Males less successful in obtaining consorts, but with potential offspring from more successful periods in the past, devoted considerable time to social contact and defence of potential offspring and their mothers. Newcomers, not very successful in obtaining consorts yet, and without offspring in the group, spent their scarce social time with the females with whom they also consorted.

\section{Mating tactics.}

\subsection{Number and total duration of the consorts obtained.}

Fig. 6 gives the number of consorts and the total duration of consorts per male, expressed as percentages of the total for all males (with a correction for absence). The graphs clearly show that the two parameters are closely 


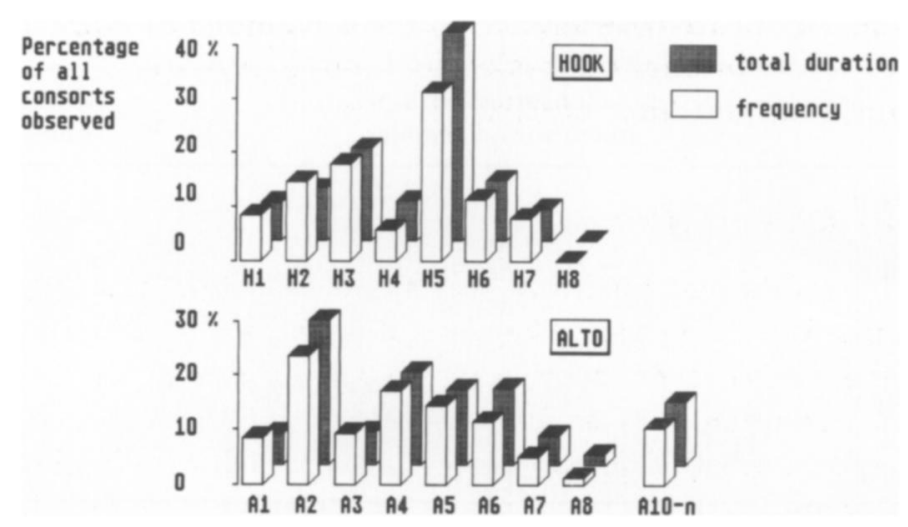

Fig. 6. Relative frequencies and total duration of the consorts obtained. The data have been corrected for absence.

related (Spearman $\mathrm{rS} \ll 0.01$, one-tailed, for both groups). There are, however some meaningful discrepancies which will be discussed below (see Section 2.2.1.).

At first glance the distribution of consorts over the adult males may seem to be quite different for the two study groups, but several aspects are in fact quite similar. This becomes clear when one remembers that Hook's Group had two high ranking newcomers (H1, H2) and Alto's Group one (A1). Thus the positions of H3-H4 correspond with A2-A3 rather than with A3-A4. The most striking difference between the groups is caused by the remarkable success of $\mathrm{H} 5$ compared to the male in the corresponding position A4. Both males relatively often used the 'combo' tactic (see below). H5 could, however, claim many more consorts after successful coalitions than could A4, because he had a special position, the 'veto-player' position (Nö̈, 1990).

One fact becomes clear from both graphs: the mating success of males, measured as total number of consorts obtained, or total time in consort, is not correlated in a linear way to rank, although some degree of correlation is apparent for the subgroup of the middle and low ranking males. (Spearman rank-correlation between agonistic rank and number of consorts: Hook's Group rS $=0.43$, NS; Alto's Group (without natal male A10) $r s=0.50, \mathrm{NS}$, one-tailed tests). A similar result is obtained, when real rank is taken instead of the imaginary rank used in the above analysis. 
Conclusion 2.1.: Mating success was not correlated to agonistic rank among the adult immigrant males in both groups judging from the number and total duration of consorts obtained.

\subsection{Quality differences of consorts.}

Consorts have different qualities, i.e. the chances that offspring is sired are not equal for all consorts. Consorts of high and low quality could be unevenly distributed over the males, thus e.g. explaining the lack of correspondence between rank and mating success.

There are a number of quality attributes, of which we will discuss four: duration, timing in relation to ovulation, likelihood of fertility of the menstrual cycle and starting time of the consort within the day. For each attribute we classified the consorts in 'high' and 'low' quality (in the sense of mating success variant 2, see Introduction) in a simple manner,

TABLE 9. Relative number of 'good quality' consorts obtained according to four criteria of quality

\begin{tabular}{|c|c|c|c|c|c|}
\hline & Male & $\begin{array}{c}\text { Duration } \\
(>150 \\
\text { min. })\end{array}$ & $\begin{array}{c}\text { Timing within } \\
\text { menstrual } \\
\text { cycle }\end{array}$ & $\begin{array}{l}\text { Potential } \\
\text { fertility of } \\
\text { cycle }\end{array}$ & $\begin{array}{c}\text { Timing } \\
\text { within day } \\
\text { (1st consort) }\end{array}$ \\
\hline \multirow[t]{7}{*}{ Hook } & $\mathrm{H} 1$ & $(-)$ & $(+)$ & - & $(+)$ \\
\hline & $\mathrm{H} 2$ & -- & $(-)$ & $(+)$ & +++ \\
\hline & H3 & $(-)$ & $(-)$ & + & +++ \\
\hline & $\mathrm{H} 4$ & $(+)$ & $(+)$ & $(-)$ & $(-)$ \\
\hline & H5 & + & $(+)$ & $(+)$ & -- \\
\hline & H6 & $(+)$ & $(+)$ & $(-)$ & --- \\
\hline & $\mathrm{H} 7$ & $(-)$ & - & $(+)$ & $(-)$ \\
\hline \multicolumn{2}{|c|}{$\begin{array}{l}\text { Overall } \chi^{2}: \\
(\mathrm{df}=6)\end{array}$} & 18.4 & 11.2 & 15.3 & 42.3 \\
\hline \multirow[t]{8}{*}{ Alto } & $\mathrm{A} 1$ & $(-)$ & $(+)$ & +++ & + \\
\hline & A2 & $(+)$ & $(+)$ & $(-)$ & +++ \\
\hline & A3 & $(-)$ & $(-)$ & $(+)$ & $(-)$ \\
\hline & A4 & $(+)$ & $(-)$ & $(-)$ & -- \\
\hline & A5 & $(-)$ & $(+)$ & $(+)$ & --- \\
\hline & A6 & $(+)$ & $(-)$ & $(+)$ & $(-)$ \\
\hline & A7 & $(+)$ & $(+)$ & $(-)$ & $(-)$ \\
\hline & A $10-n$ & $(-)$ & $(-)$ & -- & +++ \\
\hline \multicolumn{2}{|c|}{$\begin{array}{l}\text { Overall } \chi^{2}: \\
(\mathrm{df}=7)\end{array}$} & 5.6 & 7.5 & 21.2 & 46.1 \\
\hline
\end{tabular}

(See text for descriptions of criteria.) $(+) /(-)$ : difference not significant, sign given for trend only. $+/-:|z|>1.96$ (Everitt criterion). $+++/---$ : Hook's group: $|z|>2.63$, Alto's group: $|z|>2.69$ (Dunn-Sidak criterion). 
such that the difference between categories would be maximal. All tests are analyses of adjusted residuals, based on the two-tailed $\chi^{2}$-test. The tests reveal whether or not some males obtained high quality consorts, proportional to the total number of consorts they obtained. The absolute number of high quality consorts obtained is considered thereafter (Section 2.3.). An overview of the results is given in Table 9. The males A9 and H8/A8 are omitted, because they had no, respectively one consort.

Quality criterion 1: duration.

The consorts were split in 'short consorts' (30-150 minutes) and 'long consorts' (>150 minutes). Consorts were assumed not to last more than one day. There was a weak general tendency for newcomers to have relatively short consorts; this was only significant, however, in the case of $\mathrm{H} 2$.

Quality criterion 2: day of menstrual cycle.

Consorts on the days on which ovulation was likely to take place (D-5 through D-2) were compared to consort on all other days. No single male was found to deviate significantly according to the Dunn-Sidak criterion. Male $\mathrm{H} 7$ had relatively few consorts on the days around the ovulation: the adjusted residual (-2.32) was significant on the 0.05 level (i.e. according to the Everitt criterion). No general trend could be recognized with respect to this quality-criterion.

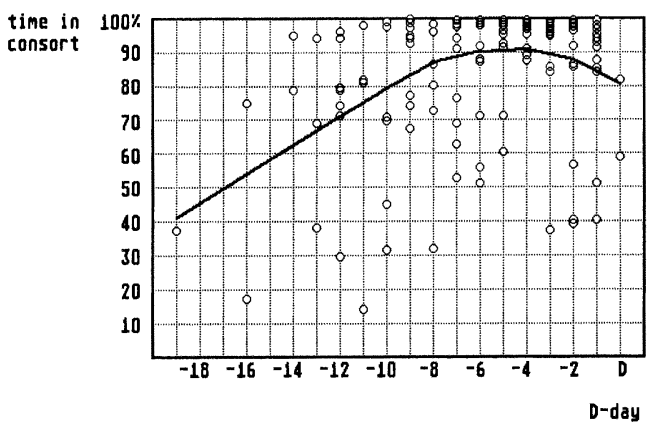

Fig. 7. The interest of males in females on different days of the menstrual cycle. X-axis: days of the cycle; the days are counted backwards from the first day on which a deflation of the sexual skin is observed (marked D). Y-axis: the total time a female was consorted by any male as a percentage of the total observation time at the $\mathrm{D}$-day concerned. The curve gives the cubic polynomial regression $\left(-0.013 x^{3}-0.608 x^{2}-4.653 x+81.186\right)$ with a maximum at $\mathrm{D}$-day $-4.46\left(\mathrm{R}^{2}=0.146, \mathrm{df}=138, \mathrm{p}<0.001\right)$. 
The question arises, whether the males are informed well enough about the timing of the ovulation. Fig. 7 shows the results of an analysis that could reveal such knowledge. The parameter for the interest that males take in a female with a sexual swelling is the total time of the day she has been in consort, expressed as a percentage of the total observation time of the day. The data for both groups are combined; four consorts with nulliparous females in their first cycle have been omitted. A polynomial regression revealed a curve with its maximum between the fifth and the fourth day before the deflation of the sex-skin. This is one to two days before the most likely day of ovulation as found in laboratorystudies. The interest of the males only slightly decreased between D-4 and D0, however. There is thus some collective preference for the days around the ovulation. The spread is considerable, however, and fairly often the males hardly competed for females in the days around the ovulation. It is possible that the shape of the curve is due to female more than to male behaviour.

Quality criterion 3: likelihood of fertility of cycles.

The criterion considered here is not whether or not conception actually took place in a menstrual cycle (this is considered in section 2.3.), but whether the quality of a cycle could possibly be 'recognized' by males. Males could be (selected to) recognize menstrual cycles as 'low quality' when certain cycles with a low average conception rate have some consistent and observable features. The conception rate of menstrual cycles of primiparous and multiparous females depends on the death or survival of the previous infant. Altmann et al. (1978) found that after the death of an infant conception was likely to take place in the first cycles (mean 2, median 1); a female with a surviving infant was likely to pass through more cycles before conception (mean and median 4). Most females do not conceive in the first year after menarche (Altmann et al., 1981), so all cycles of nulliparous females can be considered as cycles of which the chances of conception are low. To stay at the safe side we denoted all cycles of nulliparous females and all first cycles after amenorrhea of females with living last infants, as 'low quality cycles'. We assume that the males could use the same criteria.

The results (Table 9) are ambiguous. Two high ranking males (H3, A1) tended to have the 'right' consorts. A1's apparent success in picking the right consorts could be artificial, resulting from inflation due to the correction for absence (we observed only six consorts of A1). The quite 
successful, high ranking male A2 showed a trend towards low quality. Perhaps he could be less choosy, because of his high overall success. Two very young males, the high ranking immigrant $\mathrm{H} 1$ and the natal male A10, tended to consort females with 'low quality' cycles. This could point to the importance of general experience in this matter.

Quality criterion 4: time of the day.

The chance of fertilization during a consort may vary with the time of the day, when either the chance on ovulation is not evenly distributed over the 24-hour day, or copulations are not evenly distributed. To our knowledge there is no information on the exact timing of the ovulation in baboons, but it is not unlikely to be influenced by the diurnal rhythm of hormone levels. Whether or not copulations take place at night is also unknown. Our guess is that the frequency of copulations in the sleeping trees is very low, as these trees are typically rather tall and copulations would be risky. Baboons are clumsy in trees compared to most other primates. We have observed copulations in trees during the daytime, but only rarely. When there are no copulations during the night the copulation with the highest probability of fertilization would be the first copulation in the morning. The chance on fertilization later on in the day is lowered further by the formation of vaginal plugs. Thus, what may seem a rather trivial quality aspect may not be so trivial at all. Moreover, of all quality aspects it is probably the easiest perceived by the males. This reasoning is corrobated by the fact that most aggression around consorts took place in the early morning, although, on the other hand, that holds true for almost all social activity.

The distribution of the first consorts of the day (that, in addition, started before eight o'clock) was compared to the distribution of all other consorts (see Table 9). The timing in the day showed to be the only quality difference which revealed a clear trend: the top-ranking males and the natal male A10 usually obtained the early consorts. A10 occupied rank 3 and 4 respectively during the period in which he consorted females. The middle and lower ranking males often had to wait till later in the day.

Conclusion 2.2.: There is only one quality-criterion according to which the high ranking males were found to have an advantage over the low ranking males: the acquisition of consorts early in the day. 


\subsection{Likely number of offspring.}

On the basis of our own data on consorts, supplemented by data of other observers, and on the basis of data on infant-births during and after the study period, we were able to establish which males were the possible fathers of the infants (a parameter of mating success variant 1, see Introduction). We used the following categories for males seen in consort with the mothers in the cycle in which the conception took place. Possible father: no data of D-5 through D-2, but male seen in consort with the mother on the days just around that period. Likely father: male seen in consort on one of the days D-5/D-2. Probable father: the male had a virtual monopoly over matings with the mother. (The general term 'potential father' is used for a male present in the group when the infant was conceived.) The results are given in Table 10.

Conclusion 2.3.: In view of the nature of the data the only justifiable conclusion is, that reproductive success is not the monopoly of high ranking (or any other males) only.

TABLE 10. Putative number of infants sired

\begin{tabular}{lcccc}
\hline Hook's group & Possible & Likely & Probable & Total \\
H1 & & & & 0 \\
H2 & 2 & & & 2 \\
H3 & & 1 & 1 & 1 \\
H4 & 1 & 1 & & 3 \\
H5 & & 1 & & 0 \\
H6 & & & & 1 \\
H7 & & 2 & & \\
Alto's group & & 2 & 1 & 2 \\
A1 & & 3 & & 0 \\
A2 & 1 & 1 & & 4 \\
A3 & & 3 & & 1 \\
A4 & & 1 & & 0 \\
A5 & & & \\
A6 & & & \\
A7 & & & \\
A8 & & & \\
A10 & & & \\
\hline
\end{tabular}

There are, of course, more putative than real fathers: moreover, on several days on which conception could have taken place no observers were with the group. 


\section{Conclusion Section 2.}

Neither mating success, measured as number of consorts obtained, nor reproductive success, estimated on the basis of number of potential offspring, was correlated with male agonistic rank. High ranking males obtained better quality consorts according to one potential criterion: the time of the day the consort was obtained.

\section{Tactics used to obtain consorts.}

\subsection{The distribution of the use of tactis over the males.}

Fig. 8 shows the distribution of the use of the three tactics over the males. We also analysed the data with the adjusted residual technique (Table 11). It should be noted that male A10-n obtained his consorts after he obtained rank 3 (later rank 4). The data on this male have been corrected such that they reflect a whole year in this position. A10's use of tactics resembled the use of tactics of a (high ranking) recent immigrant rather than of a (low ranking) longterm resident.

The males that used the 'uncontested' tactic significantly often, H7 and A6 (and A7) were 'avoiders', i.e. they had relatively low quality consorts with many females. A true 'specialist' (high quality consorts with few females, obtained with the 'uncontested' tactic) was not found. The only male that came close to the profile of a specialist was $\mathrm{H} 4$.

Conclusion 3.1.: Although it borders to an oversimplification, it can be said that solo is the tactic of the highest ranking males, combo the tactic of the middle-ranking males, and the lowest ranking males get their consorts contest-free.

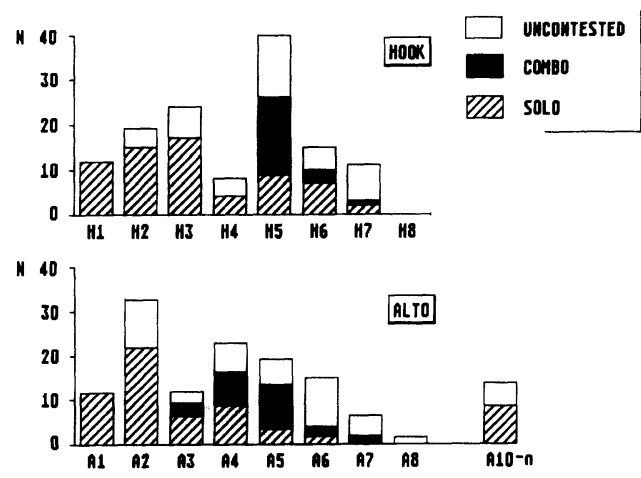

Fig. 8. The number of consorts obtained using different tactics. See Methods for a definition of the different tactics. The data have been corrected for absence. 
TABLE 11. The distribution of the use of tactics

\begin{tabular}{ccccc}
\hline & Male & Uncontested & $\begin{array}{c}\text { Tactic } \\
\text { Solo }\end{array}$ & Combo \\
\hline Hook & H1 & - & +++ & $(-)$ \\
& H2 & $(-)$ & + & - \\
& H3 & $(-)$ & + & - \\
& H4 & $(+)$ & $(-)$ & $(-)$ \\
& H5 & $(+)$ & --- & $(+)$ \\
& H6 & $(+)$ & $(-)$ & $(-)$
\end{tabular}

Overall $\chi^{2}: 57.4, \mathrm{df}=12, \mathrm{p} \ll 0.001$

$\begin{array}{clccc}\text { Alto } & \text { A1 } & - & +++ & (-) \\ \text { A2 } & (-) & + & -- \\ \text { A3 } & (-) & (+) & (+) \\ \text { A4 } & (-) & (-) & + \\ \text { A5 } & (-) & -- & +++ \\ \text { A6 } & +++ & - & (-) \\ \text { A7 } & + & (+) & -\end{array}$

Overall $\chi^{2}: 67.2, \mathrm{df}=14, \mathrm{p} \ll 0.001$

$(+) /(-)$ : difference not significant, sign given for trend only, $+/-:|z|>1.96$ (Everitt criterion). $+++/---$ : Hook's group: $|z|>2.87$, Alto's group: $|z|>2.92$ (Dunn-Sidak criterion).

\subsection{The quality of the consorts obtained with the three tactics.}

A summary of the results is given in Table 12. The use of tactics that involve agonistic conflict is strongly linked to the time of the day on which the consort is obtained: early consorts were obtained, or maintained, mainly by the solo-tactic, the combo tactic played an important role in subsequent take-overs. This result might be an artifact, resulting from the fact that the start of the first consort of the day was relatively often not observed and therefore the classification of the tactic used was more often based on the way it was defended. Nevertheless the result makes perfect sense. The first consorts of the day are usually formed in the sleeping tree, in which it is hard to manoeuver in such a way that effecrive coalitions are formed. Therefore single males with good fighting ability have the advantage as long as the female is in a tree. Males forming coalitions, however, are relatively better off on the ground, where they can surround the consorting males and attack simultaneously (see also Smuts, 1985, and references given there). 
TABLE 12. The relationship between the quality of a consort and the tactic that was used to obtain or maintain it

\begin{tabular}{|c|c|c|c|c|c|c|}
\hline \multirow[t]{2}{*}{ Quality criterion } & \multirow[t]{2}{*}{ Group } & \multirow[t]{2}{*}{ Tactic } & \multicolumn{2}{|c|}{ High quality } & \multicolumn{2}{|c|}{ Low quality } \\
\hline & & & Obs. & Exp. & Obs. & Exp. \\
\hline \multirow[t]{8}{*}{ Duration } & Hook & uncontested & 13 & 17.14 & 29 & 24.86 \\
\hline & & solo & 33 & 25.30 & 29 & 36.70 \\
\hline & & combo & 5 & 8.57 & 16 & 12.43 \\
\hline & & \multicolumn{5}{|c|}{$\chi^{2}=8.16, \mathrm{df}=2, \mathrm{p}=0.017$} \\
\hline & Alto & uncontested & 15 & 16.13 & 33 & 31.88 \\
\hline & & solo & 17 & 18.14 & 37 & 35.86 \\
\hline & & combo & 11 & 8.73 & 15 & 17.27 \\
\hline & & \multicolumn{5}{|c|}{$\chi^{2}=1.11, \mathrm{df}=2, \mathrm{p}=0.574$} \\
\hline \multirow{8}{*}{$\begin{array}{l}\text { Timing within } \\
\text { menstrual cycle }\end{array}$} & Hook & uncontested & 15 & 17.47 & 27 & 24.53 \\
\hline & & solo & 27 & 25.79 & 35 & 36.21 \\
\hline & & combo & 10 & 8.74 & 11 & 12.26 \\
\hline & & \multicolumn{5}{|c|}{$\chi^{2}=1.01, \mathrm{df}=2, \mathrm{p}=0.604$} \\
\hline & Alto & uncontested & 14 & 21.75 & 34 & 26.25 \\
\hline & & solo & 28 & 24.47 & 26 & 29.53 \\
\hline & & combo & 16 & 11.78 & 10 & 14.22 \\
\hline & & \multicolumn{5}{|c|}{$\chi^{2}=8.74, \mathrm{df}=2, \mathrm{p}=0.126$} \\
\hline \multirow{8}{*}{$\begin{array}{l}\text { Potential fertility } \\
\text { of cycle }\end{array}$} & Hook & uncontested & 18 & 15.46 & 24 & 26.54 \\
\hline & & solo & 23 & 22.82 & 39 & 39.18 \\
\hline & & combo & 5 & 7.73 & 16 & 13.27 \\
\hline & & \multicolumn{5}{|c|}{$\chi^{2}=2.19, \mathrm{df}=2, \mathrm{p}=0.335$} \\
\hline & Alto & uncontested & 32 & 24.75 & 16 & 23.25 \\
\hline & & solo & 24 & 27.84 & 30 & 26.16 \\
\hline & & combo & 10 & 13.41 & 16 & 12.59 \\
\hline & & \multicolumn{5}{|c|}{$\chi^{2}=7.27, \mathrm{df}=2, \mathrm{p}=0.026$} \\
\hline \multirow{8}{*}{$\begin{array}{l}\text { Timing within } \\
\text { the day }\end{array}$} & Hook & uncontested & 16 & 18.14 & 26 & 23.86 \\
\hline & & solo & 37 & 26.78 & 25 & 35.22 \\
\hline & & combo & 1 & 9.07 & 20 & 11.93 \\
\hline & & \multicolumn{5}{|c|}{$\chi^{2}=19.95, \mathrm{df}=2, \mathrm{p}<0.001$} \\
\hline & Alto & uncontested & 22 & 22.88 & 26 & 25.13 \\
\hline & & solo & 38 & 25.73 & 16 & 28.27 \\
\hline & & combo & 1 & 12.39 & 25 & 13.61 \\
\hline & & \multicolumn{5}{|c|}{$\chi^{2}=31.24, \mathrm{df}=2, \mathrm{p}<0.001$} \\
\hline
\end{tabular}

(For a description of quality-criteria see section 2.2.)

The results concerning the other quality parameters are ambiguous. For the parameters 'duration' and 'timing within the cycle' the 'uncontested' tactic tended to yield consorts of low quality. A rather unexpected result is that consorts in potentially fertile cycles were relatively often obtained without competition, a result that was signifi- 
cant for Alto's Group. This can partly be explained by the fact that some older, low ranking males showed more interest in the oestrous females in the right cycles, but on days far from the likely date of ovulation.

Conclusion 3.2.: Consorts started in the early morning were frequently obtained or defended with the help of the solo tactic. Otherwise none of the tactics was used exceptionally often to obtain high-quality consorts. Surprisingly, consorts in potentially fertile menstrual cycles were significantly often obtained without any contest in one group.

\section{Conclusion Section 3.}

The solo tactic, the success of which depends on individual fighting ability, is mainly the tactic of the high ranking males. This tactic was used most frequently at the start of the day. The combo tactic, the success of which highly depends on the formation of successful coalitions, is mainly used by middle ranking males and usually later in the day. Low ranking males obtained consorts mainly by default (contest-free tactic).

4. The switch from the solo tactic to the combotactic.

\subsection{Coalitions expected in a priority-of-access model.}

In the absence of males using the combo tactic, a first-ranking male should be able to claim all consorts he could handle, the second-ranking male all consorts not claimed by the first $e t c . .$. assuming that mating success is determined by priority-of-access based on agonistic dominance. When would the use of the combo tactic emerge in such a system? When two coalition partners are equally powerful they are expected to obtain the female equally often after a successful coalition. Assuming that every coalition is successful, males should switch therefore when their success at obtaining consorts single-handed drops below 0.5 i.e. less than half of their attempts to form or keep access to an oestrous female results in a consort long enough to copulate undisturbed.

As the yield of the solo tactic depends on rank according to the priorityof-access model, the number of males that can use this tactic successfully depends on the number of oestrous females available at any time. This in turn depends on three parameters: (1) the number of females, (2) the proportion of time a female is in oestrus, and (3) the extend to which the females synchronize their cycles. The expected success of a solo-player can thus be calculated on the basis of these parameters and his rank. 
A similar analysis was done by Hausfater (1975). There are some principal differences between the analysis below and HAUSFATER's approach. HAUSFATER used the number of copulations as parameter of mating success; the parameter used here is the number of consorts. HAUSFATER was interested in an estimate of reproductive success (MS1); we wanted to establish, whether males, using certain tactics, reach the goals they apparently strive for (MS2). Therefore, HAUSFATER restricted to copulations on the days around the likely ovulation (D-7 through D-1 and D-3 only), we used all consorts formed.

\subsection{Parameters of availability of oestrous females.}

Parameters 1 and 2: The number of oestrous females available.

It is assumed that the number of females simultaneously in consort was also the maximum number of females males were interested in at any day, because there were always more adult males than females with swollen sex-skins. The distribution of female/consort days should therefore reflect the number of truly interesting females available. Females were consorted during $39 \%$ of the observation time in Hook's Group and $45 \%$ of the observation time in Alto's Group. The difference between groups is mainly explained by the difference in proportion of nulliparous females (see also Quality criterion 3, section 2.2.). The minimum and maximum numbers of females available are given in Table 13.

TABLE 13. Number of oestrous females available

\begin{tabular}{|c|c|c|c|c|}
\hline & $\begin{array}{l}\text { Mature fe } \\
\text { primi/ } \\
\text { multiparous }\end{array}$ & $\begin{array}{l}\text { nulles } \\
\text { parous }\end{array}$ & $\begin{array}{l}\text { Females with } \\
\text { oestrous cycles }\end{array}$ & $\begin{array}{l}\text { Females in } \\
\text { consort }\end{array}$ \\
\hline Hook's group & $12-13$ & $1-4$ & $2-7$ & $0-4$ \\
\hline Alto's group & $17-18$ & $0-2$ & $1-8$ & $0-4$ \\
\hline
\end{tabular}

Parameter 3: Synchronisation of menstrual cycles.

Fig. 9 gives the distribution of the number of females consorted per day, based on our own data supplemented by data gathered by other researchers within the same period. The distribution found does not differ significantly from a Poisson-distribution $(\alpha=0.05)$. This means that the 


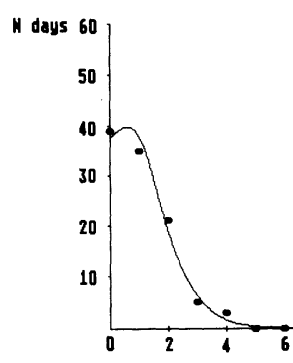

HOOK 104 fenale/consort days in 103 observation days.

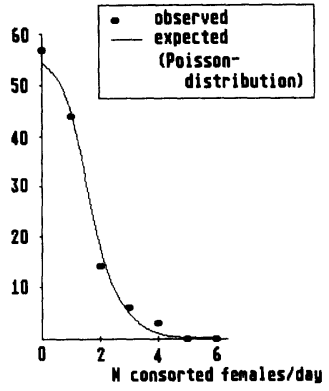

102 fenale/consort days

Fig. 9. The number of consorted females per day. The frequency distribution of the number of consorted females per day compared to a Poisson-distribution (Hook's group: mean 1.01 consort/day, Alto's Group: mean 0.823 consort/day). The observed frequencies do not differ significantly from the expected values (Kolmogorov-Smirnov onesample test).

females neither synchronized, nor avoided to cycle synchronously. This corroborates a similar result found by HAUSFATER (1975), but is at variance with the seasonality in the distribution of births found by Altmann (1980).

\subsection{Expecter' performance of males of various ranks.}

Assuming that the number of females available for the formation of consorts follows a Poisson-distribution, the performance of males, expected on the basis of the priority-of-access model (i.e. by use of the solo tactic only), can be calculated. At first we calculated the expected values under the assumption that (1) consorting males are able to monopolize a female a whole day and (2) no male has more than one consort per day. The last assumption is a realistic one, the first will be modified below. In Table 14 the expected number of females available per rank is given as a percentage of the total number of consorts and as a proportion of the maximum number any male would be able to have, which equals the expected number of the male on rank 1.

Preliminary conclusion: under the given assumptions any male below rank 1 would gain by switching from the solo to the combo tactic in both groups, provided they could find a partner and win all disputes over consorts from the male on rank 1, thus gaining half the number of consorts of the maximum one male can handle. 
TABLE 14. Expected proportion of consorts per male (I)

\begin{tabular}{lcccccc}
\hline & Male 1 & Male 2 & Male 3 & Male 4 & Male 5 & Male 6 \\
\hline $\begin{array}{l}\text { Hook's group } \\
\text { \% of days with }\end{array}$ & & & & & & \\
$\quad \begin{array}{l}\text { a consort } \\
\% \text { of all consorts }\end{array}$ & 63.6 & 26.8 & 8.2 & 2.0 & 0.4 & 0.1 \\
$\begin{array}{l}\text { Proportion of } \\
\quad \text { maximum }\end{array}$ & 1.00 & 0.42 & 0.13 & 0.03 & 0.01 & 0.00 \\
$\begin{array}{l}\text { Alto's group } \\
\text { \% of days with }\end{array}$ & & 26.5 & 8.1 & 2.0 & 0.4 & 0.1 \\
$\quad$ a consort & 56.1 & 19.9 & 5.1 & 1.0 & 0.2 & 0.0 \\
$\begin{array}{l}\text { Prof all consorts } \\
\quad \text { maxtion of }\end{array}$ & 68.2 & 24.2 & 6.2 & 1.2 & 0.2 & 0.0 \\
\hline
\end{tabular}

Assumptions: males ranked in a linear rank order, females cycle independently, once formed a male-female combination does not change within one day.

Three things are neglected in formulating this conclusion: the fact that two males can handle more consorts than one, the effect of the use of the combo tactic by other males, including the male on rank 1, and the fact that the absolute number of consorts per day increases when the number of take-overs increases.

The picture is changed somewhat when the assumption is altered that the males are able, or willing, to monopolize consorts all day long. Males do not always keep their consorts all day, even when they are not (noticeably) forced to give them up. It is not so that only low quality consorts are given up voluntarily (see section 3.2.). What happens when males give up a certain proportion of their consorts voluntarily, where after these consorts become available to the males ranking below them? (The assumption that a male has only one consort per day is not changed, i.e. males only form consorts with females given up by other's, when they do not already had or have a consort themselves that day.)

Our estimate of the number of consorts given up voluntarily is onethird. This estimate is based on the proportion of 'contest-free' consorts, which was 0.33 for Hook's Group and 0.38 for Alto's Group. Table 15 gives the proportion of consorts available per male under those assumptions. 
TABLE 15. Expected proportion of consorts per male (II)

\begin{tabular}{lcccccc}
\hline & Male 1 & Male 2 & Male 3 & Male 4 & Male 5 & Male 6 \\
\hline $\begin{array}{l}\text { Hook's group } \\
\text { \% of days with }\end{array}$ & & & & & & \\
$\quad \begin{array}{l}\text { a consort } \\
\text { of all consorts }\end{array}$ & 63.6 & 39.1 & 18.5 & 7.5 & 2.7 & 1.0 \\
$\begin{array}{l}\text { Proportion of } \\
\text { maximum }\end{array}$ & 1.00 & 0.61 & 0.29 & 0.12 & 0.04 & 0.02 \\
$\begin{array}{l}\text { Alto's group } \\
\% \text { of days with }\end{array}$ & & 29.5 & 14.0 & 5.7 & 2.0 & 0.8 \\
$\quad \begin{array}{l}\text { a consort } \\
\text { \% of all consorts }\end{array}$ & 56.1 & 32.3 & 14.1 & 5.4 & 1.9 & 0.6 \\
$\begin{array}{l}\text { Proportion of } \\
\text { maximum }\end{array}$ & 1.00 & 0.57 & 0.25 & 0.10 & 0.03 & 0.01 \\
\hline
\end{tabular}

Assumptions: males ranked in a linear rank order, females cycle independently, males form one consort per day, one-third of the consorts is given up voluntarily and becomes available to other males.

From Table 15 it can be concluded that males ranking third or lower would gain by the combo tactic. This finding partly depends on the correctness of the estimate for the number of consorts yielded voluntarily. To give an indication of the robustness of the conclusion: the second ranking male would still not gain by playing 'combo' when the number of consorts yielded voluntarily would be 0.14 for Hook's Group and 0.23 for Alto's $r$ roup. The performance of the high ranking males will, however, be affected by the success of the combo tactic employed by the lower ranking males. The absolute number of consorts obtained by solo playing high ranking males will not be affected much, the relative number and the total length of consorts will be influenced.

When the predictions of this adjusted model are compared with the reality as reflected in Fig. 8 there still are discrepancies, due in the first place to the performance of the high ranking newcomers $(\mathrm{H} 1, \mathrm{H} 2$ and A1). Altmann's priority-of-access model predicts a high number of consorts for the male on rank 1 and a rather steep decline, as one goes down through the ranks. In reality the performance of the newcomers is much lower. Baboon immigrants can obtain a high rank very soon after their arrival. For example, four of the seven males present the day A1 immigrated, gave submission to him on that first day. It took $\mathrm{H} 1$ and $\mathrm{H} 2$ longer between their first contact and the moment they established their high rank. Neither of these newcomers, however, obtained consort regularly shortly after they became high ranking. 
The expected and observed rank of the highest ranking combo-player also shows a discrepancy in Hook's Group: in reality the main comboplayer is a lower ranking male than expected. (In Alto's Group the fit is better than apparent from Fig. 8 and Table 11. A1 was only in the group for the last two months, A4 was the third ranking male during most of the study; see Fig. 2). Which males play combo also depends, however, on the dynamics of alliance formation. These dynamics will be commented upon further in the Discussion.

\section{Conclusion Section 4.}

In the study groups, and groups with comparable demographic parameters (number of adult males 6-8, adult sex ratio 0.33-0.50), the two highest ranking males should employ the solo tactic, assuming that its performance is correctly predicted by AltmanN's 'priority-of-access' model. All other males should use the combo tactic. The discrepancy between the predicted and the observed distribution of tactics is mainly due to a lower-than-expected performance of high ranking immigrants, shortly after their arrival.

\section{Discussion}

1. The reproductive career of a male savanna baboon.

\subsection{The rank history of an archetypical male.}

The careers of individual males may differ considerably, but a pattern that can be recognized fairly often is the following: the male migrates for the first time as a young adult after a rapid growth spurt and a sudden rise in rank in the natal group. In the new group he soon reaches a high rank, sometimes after an initial period as a peripheral male (especially very young migrants). The male gradually drops in rank as more young newcomers arrive. There is a perfect correlation between rank, length of the period of residence, and age in a group consisting of such males only. We based our idea of an archetypical male career on the following studies: Packer, 1979a; Rasmussen, 1980; Ransom, 1981; Manzolillo, 1982; Strum, 1982; Bercovitch, 1985; Smuts, 1985; Collins, 1986; Altmann et al., 1988; Hausfater \& Takacs, 1987; NoË, 1989). The picture we describe here is only valid for small to medium sized groups, like those found in Amboseli. In a much larger group we studied near Gilgil, 
Kenya a similar pattern was found for the immigrant males, but since about half of the reproductively active males were natals, the social structure of the male subgroup differed considerably from the structure found in Amboseli (see also SmuTs, 1985). It should be noted, that dominance relationships between males are not as stable as between females (cf. Hausfater, 1975; Bercovitch, 1986). Especially among males of similar age and residence status frequent reversals may be expected. Wounds and illnesses may also cause temporary or permanent drops in rank.

Hook's Group, in the last period of the study, is an example of the 'ideal' group described above. The model-group pictured below is therefore mainly based on data from Hook's Group. The rank-residence correlation in Alto's Group could be recognized as a trend, but was not significant (Nö̈, 1989). The deviations were caused by the presence of two types of males that will generally cause such deviations: males that stay and mate in their natal group (example: A10-n), and males that migrate for a second, third, etc. time (examples: A8, and presumably A5).

\subsection{The relationship between rank, residence and mating success.}

Fig. 10 gives the relationship between rank and mating success arrived at through different tactics. The X-axis can be read in two ways: (1) as the reproductive career of an archetypical male baboon between his first and his second migration, or (2) as the momentary profile of a male subgroup consisting of a number of such individuals that, in addition, immigrated at regular intervals. The curves reflect the average successes associated with the different ranks. The distributions used in Fig. 10 are chosen to give a slightly exaggerated picture of the data actually observed in the two groups: but the model group of males is somewhat larger $(\mathrm{N}=11)$. The distributions are directly related to the distribution of oestrous females available (see Fig. 9). The distribution of mating success of the solo tactic is based on a Poisson-distribution with $\mu=1.5$, and the origin on rank 1; the optimal success is on rank 2 . The graph reflects the priority-of-access model for the solo tactic, taking into account the lower success of newcomers (on rank 1). The distribution of the combo tactic is based on a Poisson-distribution with $\mu=2.5$, with the origin on rank 4 (and extrapolated from this origin to the left). Rank 4 is chosen as the origin, because newcomers and males successful with the solo technique (success above $1 / 2$ of the maximum of the solo tactic) do not use the 


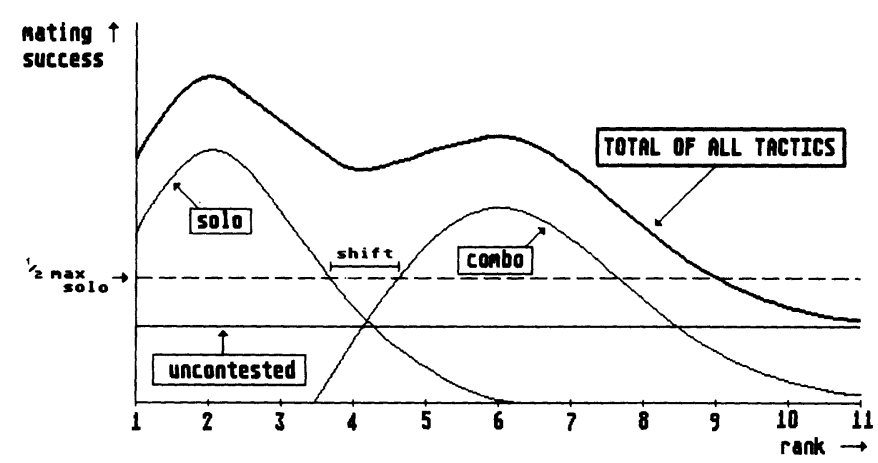

Fig. 10. The hypothetical relation between rank and mating success.

combo tactic. Above that, the data suggest an extra shift to the lower ranks, which will be discussed in section 3 below. The Poissondistribution with a mean of 2.5 reflects the wide range of ranks over which the combo tactic is successfully used, as compared to the solo tactic. We do not have a reason to suppose that the success of the contest-free tactic is dependent on rank in an absolute sense. Therefore the graph shows a straight line reflecting about one-third of all consorts obtained. Relatively speaking this tactic is important for males on rank 4 and below rank 7 .

\subsection{The importance of the post-mating tactic in a male's career.}

In addition to the yield of his mating tactics a male's reproductive success is also determined by the yield of his post-mating tactic, i.e. the support he lends to his offspring and their mothers. It is unknown what the effect of a male's behaviour on the survival of his offspring is. Highly uncertain therefore, is the importance of the effect of the post-mating tactic compared to the importance of the mating tactics. Something can be said, however, about the distribution of the use of the tactic over the males, both on theoretical, as well as on empirical grounds (see the data given in the sections 1.2 through 1.4). The importance of a male's paternal effort depends firstly on the number of infants he has in the group, which is a function of his period of residence and his mating success over that period and secondly, on the usefulness of paternal effort to the infants, which depends on the infants' age. Infants are likely to gain most from a male, when they become independent of their mother, but are still very small. Males may notably be important to infants after a younger sibling is born. 
The theoretically expected curve for reproductive success due to paternal care against rank would resemble the curve for mating success given in Fig. 10, but be shifted to the right a number of ranks (equivalent to the average drop in rank over one to two years). In the empirical data the theoretically expected curve is reflected best in the proximity of males to 'mothers' (Fig. 4).

\subsection{An archetypical reproductive career.}

The reproductive career of the 'archetypical' males goes through the following phases:

a. shortly after migration: establishing of (high) rank, low to moderate mating success, mainly through solo tactic. No paternal care.

b. Peak mating success through solo tactic, male still high ranking. No paternal care.

c. Sudden increase in paternal care for offspring sired in the first successful mating period. Less success through solo tactic, due to lower rank. Contest-free tactic relatively more important: the male 'specializes'.

d. Increase of the effectiveness of the combo tactic, combined with a relatively high investment in the post-mating tactic. Males that fail to develop coalitions and whose paternal care has little impact, emigrate.

e. Last phase in which the share gained through the combo tactic diminishes and opportunities to use the solo tactic become very scarce. Mating success mainly through the contest-free tactic; the male becomes an 'avoider'. A male in this phase emigrates as soon as the effect of paternal care on his offspring becomes insignificant.

In conclusion: mating success arrived at through the solo tactic is dependent on rank, but males that are less successful in using this tactic have an option to switch to other mating tactics, notably the formation of coalitions, and/or to non-mating reproductive tactics, notably the investment in potential offspring.

2. The pre-mating tactic: building up an asymmetry or influencing female choice?

The present data give no reason to assume an important contribution of the pre-mating tactic to the reproductive success of males in general. Most time spent with females was spent with mothers with small infants 
(Fig. 5). Males showed relatively (Fig. 4) and absolutely (Fig. 5) little interest in females during their menstrual cycles, when these females had no infants. An explanation for this lack of interest could be, that most females without living, young infants were nulliparous females, who have a lower fertility than primi- or multiparous females. The difference in relative interest in 'cycling mothers' as compared to (non-cycling) 'mothers' (Fig. 4) showed no clear pattern, which is mainly due to the relatively large contributions of individual male-female relationships to the small data sets for 'cycling mothers'.

The newcomers developed fairly strong bonds with one or two females. This may point to a greater importance of pre-mating tactics for newcomers. A strong bond with females may boost a male's future mating success in two ways. Firstly, an affinitive bond may have a positive effect on the female's cooperation during subsequent oestrous periods. Secondly, a conflict over a female among males can be decided to the advantage of the male with the stronger bond. As stated in the Introduction a strong bond of one of two contesting males can be used as an asymmetry on the basis of which the contest is resolved. The asymmetry can be a 'pay-off asymmetry', which implies an active role of the female, or an 'uncorrelated' asymmetry of the owner-rival type. Because three newcomers (A1, $\mathrm{H} 1$ and $\mathrm{H} 2$ ) were high ranking it cannot be decided whether their ownership or their strength was respected during consorts with their female 'friends'. The only observed consort of low ranking newcomer $\mathrm{H} 8$ was indeed with his 'friend'.

STRUM (1982) explains the formation of bonds of newcomers with females as a mechanism for the male to become accepted in the group, rather than as a pre-mating tactic. The mechanism postulated remains unclear. Females would not be able to expel an adult male, while resident males would rather expel males with good contacts with females. STrum reported that the newcomers especially had contact with low ranking females. This makes the interpretation of the newcomers' behaviour as a pre-mating tactic even more plausible. A male would have more chance to influence the choice of a low ranking female than of a high ranking female. Low ranking females, who lack effective support in intra-group conflicts, have more to gain from a bond with a male and would therefore be more willing to pay back a male for his services. Newcomers A1, A8 and $\mathrm{H} 2$ indeed had special contacts with females ranking below the median (15th of 19,13 th of 19 and 16th of 16 adult females respectively). The favourite female of $\mathrm{H} 1$ ranked 6 th of 16 , however. Females without close adult female kin would also have to gain more than females with 
many relatives. A1's friend had no close female relatives. A8's friend had an adult sister and the relationships of the other two females were not known with certainty, but both were likely to have close relatives among the adult females.

In conclusion: the question 'female choice' or 'asymmetry' cannot be answered conclusively with these data. In agreement with SMuts (1985), we suppose that 'female choice' is the most likely explanation, but both explanations are probably valid simultaneously. With the possible exception of newcomers, pre-mating tactics are of minor importance relative to the reproductive effort of males as a whole, however..

\section{The use of different mating tactics.}

The combo tactic implies that a male is regularly involved in risky fights over oestrous females without obtaining the consort. A male, therefore, should utilize the solo tactic as long as he is successful enough in doing so. Only for very powerful players in the coalition formation game, who were able to claim the lion's share of the yield of coalitions (e.g. H5, see NoË, 1990), was the success rate of the combo tactic comparable to that of a successful solo-player. On the basis of the priority-of-access model and the number of oestrous females available one would expect males below rank 2 to employ the combo tactic. The simplest expected group profile is then: two high-ranking solo-players, followed by a number of combo-players. In reality there were a number of deviations from this picture.

Firstly, some newcomers were high ranking, without having a high mating success. They were able to gain access to females with the solo tactic, but seemed to attempt to do so less often than high ranking males of longer residence. Hausfater (1975) found the strongest discrepancy between the priority-of-access model and his data in the performance of males on rank 1, who had a much lower than expected mating success. It is unknown, whether his males were recent immigrants. HAUSFATER's explanation for their unexpectedly low performance measured in number of copulations was their relatively high selectivity. We did not find indications for such a differentiation in selectivity, however (see section 4 below). The highest ranking two males in the group studied by Collins (1981) were newcomers, one of which had a mating success far below the expectation based on the priority-of-access model. Collins supposed that this male mated relatively often at night and in the early morning. We 
doubt whether this could explain the considerable discrepancy Collins found, since it seems unlikely that matings would take place as frequently at night as in the day-time. SMuts (1985) stated that lack of cooperation by the female explains why newcomers do not form consorts easily. If her explanation is correct, it could also explain why newcomers put relatively more effort in pre-mating tactics.

Secondly, both study groups had one male (H4, respectively A3) with a relatively low mating success, according to any parameter. These males ranked between the successful solo players and the successful combo players. There are three possible explanations for their unexpectedly low mating success.

1) The low mating success was compensated by the successful use of other reproductive tactics.

Male $\mathrm{H} 4$ devoted a considerable amount of his time (around 5 percent) to herding and guarding four mother-infant pairs. The infants were conceived in the period shortly after H4's immigration, when he was the $\alpha$ male. $\mathrm{H} 4$ wounded the then $\alpha$-male (H6) and induced several abortions, shortly after his immigration (see for an extensive description of this immigration Pereira, 1983). Presumably he thus forced a short period of high mating success, followed by a period of paternal investment to consolidate this. Male A3, a very peripheral male, did not use much time for paternal choruses, although he tended to react rather strongly to the distress signals of one particular infant (f8 in Fig. 3). The mother of this infant was significantly often in A3's proximity, but the infant itself was not.

2) Lack of cooperation by the females made consorting behaviour too ineffective.

H4 was, not surprisingly after his violent immigration, not very popular among the females; A3 was the male with the least social contacts of all males in the study. A female may not cooperate during a consort, but she is not likely to be able to prevent the male from consorting her. The behaviour of females is thus not likely to greatly influence the number of consorts a male obtains.

3) They were neither able to use the solo tactic nor the combo tactic.

Male $\mathrm{H} 4$ had two or three males ranking above him during most of the study period, so the solo tactic was not expected to yield much for him. Male A3 has been second ranking for 7.5 months and third ranking for 
5.5 months. His success using the solo tactic was lower than expected according to the priority-of-access model (expected: $27 \%$, observed $13 \%$ of all consorts obtained with the solo tactic) and also relative to the male ranking above him (A2). Male A2, who had ranking 1 for ten months and rank 2 for two months obtained $41 \%$ (expected $52 \%$ ). According to the model male A3 should have had one half of the number of consorts of A2, but he obtained one-third. One reason for A3's low performance could be that his share was reduced as a result of the success of the combo players ranking below him.

Why did $\mathrm{H} 4$ and A3 not use the combo tactic more often? For a majority of the consort take-overs with the help of other males coalitions have to be formed. Few consorts can be obtained by making opportunistic use of the efforts of other males. A3 obtained three consorts by using the combo tactic, all by stealing females that were unattended during a conflict of the consorting male and a challenger. So far two explanations have been given, why some males that could improve their mating success by forming coalitions nevertheless fail to do so. One explanation is that males have to know each other rather well to be able to form coalitions (SMUTs, 1985). Males of short residence are therefore not expected to form coalitions. This could explain the case of $\mathrm{H} 4$, but not of A3, who was in the group for 14 months at the start of the study, as long or longer than other males that frequently formed coalitions (A5, $\mathrm{H} 5, \mathrm{H} 6)$.

A theoretical explanation can be constructed with the help of the theory of Coalition games. The 'minimum resource theory' (GAMson, 1961), which is discussed more extensively elsewhere (Nö̈, 1989, 1990) predicts that the weakest coalition able to operate successfully is formed. The mechanism behind this is that each individual tries to form a coalition with the weakest possible partner in order to reduce the burden of competition within the coalition. So each group may have males that are too weak to be successful on their own, but too strong to be accepted as a regular coalition partner. Such males have three options: invest in pre/post mating efforts, emigrate, or wait for changes in the male subgroup. We doubt whether they could disguise themselves as more modest coalition partners, since that would imply that they would have to act in a less dominant way in almost any competitive situation.

Because we do not expect the presence of male such as $\mathrm{H} 4$ and $\mathrm{A} 3$ to be incidental, we adjusted the expected distribution in the model given in Fig. 10 in such a way that the curves for the 'solo' and the 'combo' tactic intersect each other below the line indicating the $1 / 2$ maximum 
value of a successful solo player. The curve for the 'combo' tactic is shifted to the right over a distance equivalent to 1 rank distance (indicated with 'shift' in Fig. 10).

\section{Male mating selectivity.}

There have been many suggestions in the primate literature about the selectivity of males. The mating success of high ranking males would only appear to be moderate, but because of their high selectivity their ultimate reproductive success would nevertheless be high. What information would baboon males be able to use as a basis for selectiveness? Baboons do not have a concealed ovulation. In retrospect one is able to know almost exactly the moment of ovulation in a fertile cycle. But does that mean that the males know when the ovulation is about to take place? The results presented in section 2.2.2. of the Results suggest that they collectively put most emphasis on the days around the ovulation. No single individual was, however, able to select the days around the ovulation better than others did. This is in agreement with the conclusion reached by BERCOVITCH (1987) on the basis of his own data and a reanalysis of data presented by Hausfater (1975) and PAGker (1979): high ranking males may be selective with respect to cycle-day in relation to their own mating activity, but they do not differ in that respect from other adult males.

Experiments by BIELERT \& van der WALt (1982) suggest that males mainly use visual cues, especially the size of the perineal swelling, to determine the most likely moment of ovulation. With most females it is hard for an observer to see changes in the sexskin size between D-7 till D-1. Males may therefore have to rely in some way on the time elapsed since the female reached her maximum swelling. Size per se does not suffice, because of the considerable individual differences between females. A selective male has to know the shape and size of the maximum swelling of each female. In this respect males of long residence, who are in most cases generally more experienced too, have an advantage over the young males of short residence.

Males are likely to be able to tell apart nulliparous females, which have low fertility, from primi/multiparous females. Generalists will therefore not bet on nulliparous males, but specialists that do (e.g. H4) may sire an infant of which their paternity is quite certain. It will be almost impossible for a male to tell whether a menstrual cycle is anovulatory or ovulatory. That a consort is the first of the day is a quality aspect that 
is easy to recognize for any male. The fact that high ranking males selectively claimed those consorts is, most likely, partly explained by their preference and partly by the fact that they had to for tactical reasons.

The question remains, how selective males could be, given the information they have. Some more insight may be gained when the problem is viewed from the female stand-point. One option female baboons hardly have is regulating the identity and number of partners by direct female choice based on behaviour (SMUts, 1985). Which males are females likely to prefer? In view of the baboon ranking system in which males start high ranking and gradually drop there are no strong 'genetic' reasons to choose high ranking males. Perhaps high ranking males would make good fathers, provided that they are willing to invest in paternal care. In this study the highest ranking males were, however, not willing to do so as long as they kept there high rank (see e.g. male A2).

What would be the optimal number of males that act as if they had sired her infant? We suppose that there is an optimum for the female of two or three of such males. More males would increase the uncertainty of paternity too much and therefore the willingness to invest in the offspring. One male with an almost $100 \%$ certainty would also not be optimal. Firstly, there would be no 'spare father' to protect the infant, when the male dies or emigrates. Secondly, one male would not be enough to protect an infant from an infant-killing immigrant. High ranking, infant killing immigrants are a serious problem for baboon females (Busse \& Hamilton, 1981; Pereira, 1983). Single resident males would normally not be very successful in attempts to prevent the infant-killing by such a male, nor would a coalition of females. The only effective opposition can be expected from a coalition of adult males. With a fairly good, but not too precise indication of the moment of ovulation female baboons would induce the formation of such coalitions of two or three males, since these males would all be motivated on the grounds of the fairly high chance of being the father of her infant. It is interesting to note in this respect that ovulation is concealed in primate species in which twothree male coalitions are not possible (single-male species), not sufficient (species with raids by all-male bands), or not necessary (species in which newcomers are low ranking; data given in HRDY \& WhitTen, 1987). Thus we suggest that males cannot be very selective due to selection for female strategies that prevent such selectivity. 


\section{Summary}

The strongly related parameters rank, age and period-of-residence determine which reproductive tactics a savanna baboon male will use primarily. Baboon males go through the following phases with respect to the use of mating tactics, as they are longer in the group and thus grow older and, as a rule, drop in rank:

Phase 1. Peripheral, relatively little social contact, low mating success, building up of a social bond with a few females.

Phase 2. High mating success, based on individual fighting ability, social bonds mainly with females that are, or will soon be, sexually attractive.

Phase 3, variant a. (Males that were very successful in Phase 2). Considerable time devoted to guarding infants conceived in phase 2 and to the mothers of those infants. Mating activity drops sharply compared to Phase 2.

Phase 3, variant b. (Males that did not go through a very successful Phase 2). Low mating success through whatever tactic, relatively peripheral.

Phase 4. Relatively high mating success, partly through collaboration with other males. Considerable time is invested in the care for potential offspring and their mothers.

Phase 5. Diminishing share in the total mating activity in the group. The support for infants is spread over a relatively large class of infants conceived after immigration. Social contact with a large number of females.

The data did not show the relation between agonistic rank and mating success predicted by AltmanN's priority-of-access model. A modification of the model is presented, which allows for coalition formation among males that are too low in rank to be successful on their own. This model could not fully explain, however, the exceptional success of some middle ranking males. The theory of Coalition games can give insight in the processes that lead to distributions of mating success that depart from the modified priority-of-acces model.

The lack of agreement between the data and the original priority-of-access model cannot be explained by higher selectivity of the high ranking males. The only qualitative parameter of consorts obtained, according to which high ranking males had an advantage, is the time of the day on which mating activity takes place. This is a direct result of the way in which males obtain their consorts. Consorts are often formed in the sleeping trees during the night or in the early morning. In that situation single, strong males have an advantage in conflicts against coalitions of lower ranking males. Lower ranking males have a relative advantage later in the day, when conflicts are fought out on the ground.

\section{References}

Altmann, J. (1974). Observational study of behavior: sampling methods. - Behaviour 49, p. 227-267.

- - (1980). Baboon mothers and infants. - Harvard Univ. Press, Cambridge, Mass.

$\rightarrow--$, Altmann, S. A. \& Hausfater, G. (1978). Primate infant's effects on mother's future reproduction. - Science 201, p. 1028-1030.

- - - _ \& - (1981). Physical maturation and age estimates of yellow baboons, Papio cynocephalus, in Amboseli National Park, Kenya. - Am. J. primatol. 1, p. 389-399.

- - Hausfater, G. \& Altmann, S. A. (1988). Determinants of reproductive success in savanna baboons, Papio cynocephalus. - In: Reproductive success. Studies of individual variation in contrasting breeding systems (T. H. Clutton-Brock, ed.). Univ. Chicago Press, Chicago, p. 403-418.

Altmann, S. A. (1962). A field study of the sociobiology of the rhesus monkey, Macaca mulatta. - Ann. N. Y. Acad. Sci. 102, p. 338-435. 
Bachmann, C. \& Kummer, H. (1980). Male assessment of female choice in Hamadryas baboons. - Behav. Ecol. Sociobiol. 6, p. 315-321.

Bercovitch, F. B. (1983). Time budgets and consortships in olive baboons (Papio anubis). - Folia primatol. 41, p. 180-190.

- - (1985). Reproductive tactics in adult female and adult male olive baboons. - Ph.D. thesis. Univ. of California, Los Angeles.

- (1986). Male rank and reproductive activity in savanna baboons. - Int. J. Primatol. 7, p. 533-550.

$\rightarrow-$ (1987). Reproductive success in male savanna baboons. - Behav. Ecol. Sociobiol. 21, p. 163-172.

- (1988). Coalitions, cooperation, and reproductive tactics among adult male olive baboons. - Anim. Behav. 36, p. 1198-1209.

Berenstain, L. \& WADE, T. D. (1983). Intrasexual selection and male mating strategies in baboons and macaques. - Int. J. primatol. 4, p. 201-235.

Bielert, C. \& Walt, L. A. van der (1982). Male chacma baboon (Papio ursinus) sexual arousal; mediation by visual cues from female conspecifics. - Psychoneuroendocrinology 7, p. 31-48.

Busse, C. D. (1984). Triadic interactions among male and infant chacma baboons. In: Primate paternalism (D. M. TAUB, ed.). Van Nostrand Reinhold, New York, p. 186-212.

$\rightarrow-$ \& Hamilton, W. J. (1981). Infant carrying by male chacma baboons. - Science 212 , p. $1281-1283$.

Collins, D. A. (1981). Social behaviour and patterns of mating among adult yellow baboons (Papio c. cynocephalus L. 1766). - Ph.D. thesis. Univ. of Edinburgh.

- (1986). Interactions between adult male and infant yellow baboons (Papio c. cynocephalus) in Tanzania. - Anim. Behav. 34, p. 430-443.

Curie-Cohen, M., Yoshihara, D., Luttrell, L., Benforado, K., Maccluer, J. W. \& Stone, W. H. (1983). The effects of dominance on mating behavior and paternity in a captive troop of rhesus monkeys (Macaca mulatta). - Am. J. primatol. 5, p. 127-138.

DeVore, I. (1965). Male dominance and mating behavior in baboons. - In: Sex and behavior (F. A. BeAch, ed.). John Wiley \& Sons, New York, p. 266-289.

Deag, J. M. \& Crook, J. H. (1971). Social behaviour and 'agonistic buffering' in the wild Barbary macaque Macaca sylvana L. - Folia primatol. 15, p. 183-200.

Drickamer, L. C. (1974). Social rank, observability, and sexual behaviour of rhesus monkeys (Macaca mulatta). - J. Reprod. Fert. 37, p. 117-120.

Dunbar, R. I. M. (1988). Primate social systems. - Croom Helm, London.

Everitt, B. S. (1977). The analysis of contingency tables. - Chapman and Hall, London.

$\rightarrow$ Gamson, W. A. (1961). A theory of coalition formation. - Am. Soc. Rev. 26, p. 373-382.

Harding, S. O. (1980). Agonism, ranking, and the social behavior of adult male baboons. - Am. J. phys. Anthropol. 53, p. 203-216.

Hausfater, G. (1975). Dominance and reproduction in baboons. - Monograph, Contributions to primatology series, Karger, Basel.

- \& T TAKACS, D. (1987). Structure and function of hindquarter presentations in yellow baboons (Papio cynocephalus). - Ethology 74, p. 297-319.

Hendrickx, A. G. \& Kraemer, D. C. (1969). Observations on the menstrual cycle, optimal mating time and pre-implantation embryos of the baboon, Papio anubis and Papio cynocephalus. - J. Reprod. Fert. Suppl. 6, p. 119-128.

Hrdy, S. B. \& Whitten, P. L. (1987). Patterning of sexual activity. - In: Primate societies (B. B. Smuts, D. L. Cheney, R. M. Seyfarth, R. W. Wrangham \& T. T. Struhsaker, eds). Univ. Chicago Press, Chicago, p. 370-384. 
Huffmann, M. A. (1987). Consort intrusion and female mate choice in Japanese macaques (Macaca fuscata). - Ethology 75, p. 221-234.

$\rightarrow$ Kummer, H., Götz, W. \& Angst, W. (1974). Triadic differentiation: an inhibitory process protecting pair bonds in baboons. - Behaviour 49, p. 62-87.

Loy, J. D. (1971). Estrous behavior of free-ranging rhesus monkeys (Macaca mulatta). Primates 12, p. 1-31.

Manzolillo, D. L. (1982). Intertroop transfer by adult male Papio anubis. - Ph.D. thesis. Univ. of California, Los Angeles.

Maynard Smith, J. \& Parker, G. A. (1976). The logic of asymmetric contests. - Anim. Behav. 24, p. 159-175.

Nö̈, R. (1986). Lasting alliances among adult male savannah baboons. - In: Primate ontogeny, cognition and social behaviour (J. G. Else \& P. C. LeE, eds). Cambridge Univ. Press, Cambridge, p. 381-392.

- (1989). Coalition formation among male baboons. - Thesis, Univ. of Utrecht.

$\rightarrow-1$ (1990). A Veto game played by baboons: a challenge to the use of the Prisoner's Dilemma as a paradigm for reciprocity and cooperation. - Anim. Behav. 39, p. 78-90.

- -, WaAl, F. B. M. de \& Hooff, J. A. R. A. M. van (1980). Types of dominance in a chimpanzee colony. - Folia primatol. 34, p. 90-110.

Noordwijk, M. A. van (1985). Sexual behaviour of Sumatran longtailed macaques (Macaca fascicularis). - Z. Tierpsychol. 70, p. 277-296.

- - \& Schaik, C. P. van (1988). Male careers in Sumatran longtailed macaques (Macaca fascicularis). - Behaviour 107, p. 24-43.

$\rightarrow$ PACKer, C. (1977). Reciprocal altruism in Papio anubis. - Nature 265, p. 441-443.

- (1979). Male dominance and reproductive activity in Papio anubis. - Anim. Behav. 27, p. $37-45$.

- (1980). Male care and exploitation of infants in Papio anubis. - Anim. Behav. 28, p. $512-520$.

Pereira, M. E. (1983). Abortion following the immigration of an adult male baboon (Papio cynocephalus). - Am. J. primatol. 4, p. 93-98.

- (1989). Agonistic interactions of juvenile savanna baboons. II. Agonistic support and rank acquisition. - Ethology 80, p. 152-171.

Popp, J. L. (1978). Male baboons and evolutionary principles. - Ph.D. thesis. Harvard Univ., Harvard.

Ransom, T. W. (1981). Beach troop of the Gombe. - Bucknell Univ. Press. Lewisburg, Penn.

- - \& Ransom, B. S. (1971). Adult male-infant relations among baboons (Papio anubis). - Folio primatol. 16, p. 179-195.

Rasmussen, D. R. (1980). Clumping and consistency in primates' patterns of range use: definitions, sampling, assessment and application. - Folia primatol. 34, p. 111-139.

RASMUSSEN, K. L. R. (1983). Influence of affiliative preferences upon the behaviour of male and female baboons during sexual consortship. - In: Primate social relationships (R. A. Hinde, ed.). Blackwell, Oxford, p. 116-120.

Rowell, T. E. (1966). Hierarchy in the organization of a captive baboon group. Anim. Behav. 14, p. 430-443.

SAAYMAn, G. S. (1971). Behaviour of the adult males in a troop of free-ranging Chacma baboons (Papio ursinus). - Folia primatol. 15, p. 36-57.

Shaikh, A. A., Celaya, C. L., Gomez, I. \& Shaikh, S. A. (1982). Temporal relationship of hormonal peaks to ovulation and sex skin deturgescence in the baboon. Primates 23, p. 444-452.

Shively, C. \& Smith, D. G. (1985). Social status and reproductive success of male Macaca fascicularis. - Am. J. primatol. 9, p. 129-135. 
Smuts, B. B. (1983). Dynamics of 'special relationships' between adult male and female olive baboons. - In: Primate social relationships (R. A. Hinde, ed.). Blackwell, Oxford, p. 112-116.

- (1985). Sex and friendships in baboons. - Aldine, Hawthorne, N.Y.

Sokal, R. R. \& RohlF, F. J. (1981). Biometry: The principles and practice of statistics in biological research. 2nd edition. - Freeman, San Francisco.

Stein, D. M. (1984). Ontogeny of infant-adult male relationships during the first year of life for yellow baboons (Papio cynocephalus). - In: Primate paternalism (D. M. TAUB, ed.). Van Nostrand Reinhold, New York, p. 213-243.

Stern, B. R. \& Smith, D. G. (1984). Sexual behaviour and paternity in three captive groups of rhesus monkeys (Macaca mulatta). - Anim. Behav. 32, p. 23-32.

Strum, S. C. (1982). Agonistic dominance in male baboons: an alternative view. - Int. J. primatol. 3, p. 175-202.

- (1984). Why males use infants. - In: Primate paternalism (D. M. TAuB, ed.). Van Nostrand Reinhold, New York, p. 146-185.

$\rightarrow$ Tutin, C. E. G. (1979). Mating patterns and reproductive strategies in a community of wild chimpanzees (Pan troglodytes schweinfurthii). - Behav. Ecol. Sociobiol. 6, p. 29-38.

WAAL, F. B. M. de (1977). The organization of agonistic relations within two captive groups of Java-monkeys (Macaca fascicularis). - Z. Tierpsychol. 44, p. 225-282.

- - (1987). Dynamics of social relationships. - In: Primate societies (B. B. Smuts, D. L. Cheney, R. M. Seyfarth, R. W. Wrangham \& T. T. Struhsaker, eds). Univ. Chicago Press, Chicago, p. 421-429.

\section{Zusammenfassung}

Die eng verknüpften Factoren Dominanzrang, Alter und Dauer der Gruppenzugehörigkeit beeinflussen, welche Fortpflanzungstaktik Savannen-Pavian Männchen bevorzugt einsetzen. Je länger die Männchen in der Gruppe sind und je älter sie werden, desto mehr verlieren sie in der Regel an Rang, wobei sie die folgenden Phasen unterschiedlicher Fortpflanzungstaktiken durchlaufen:

Phase 1: Peripher, relativ wenig Sozialkontakte, geringer Fortpflanzungserfolg, Aufbau enger sozialer Beziehungen zu einigen wenigen Weibchen.

Phase 2: Hoher Fortpflanzungserfolg basierend auf individueller Kampfkraft, sozialer Beziehungen beforzugt zu Weibchen, die sexuell attraktiv sind oder es in Kürze sein werden.

Phase 3: Variante a (Männchen, die in Phase 2 erfolgreich waren): Zeitaufwendiges Behüten der Jungtiere, die in Phase 2 gezeugt wurden, sowie ihrer Mütter. Deutliche Abnahme des Fortpflanzungserfolgs gegenüber Phase 2.

Phase 3: Variante b (Männchen, die in Phase 2 nicht sehr erfolgreich waren): Verschiedenen Fortpflanzungstaktiken, aber generell geringer Fortpflanzungserfolg, relativ peripher.

Phase 4: Relativ hoher Fortpflanzungserfolg, teilweise mittels Zusammenarbeit mit anderen Männchen. Zeitaufwendiges Behüten potentieller Nachkommen und ihrer Mütter.

Phase 5: Abnehmende Fortpflanzungstätichkeit. Regelmässiges Unterstützen von Jungtiere, die nach der Einwanderung des Männchens in die Gruppe gezeugt wurden, in agonistischen Auseinandersetzungen. Sozialkontakte zu vielen Weibchen.

Die Daten belegen keine positive Korrelation zwischen dem Dominanzrang und der Fortpflanzungstätigkeit, wie sie gemäss AltmanN's 'Priority-of-access' Modell zu erwar- 
ten wäre. Eine modifizierte Version dieses Modells berücksichtigt, dass Männchen, die zu rangtief sind um aus eigener Kraft erfolgreich zu sein, koalitionen bilden können. Dieses erweiterte Modell vermag jedoch die ausserordentliche hohe Fortpflanzungstätigkeit einiger mittelrangiger Männchen nicht vollständig zu erklären. Spieltheoretische Überlegungen zur Koalitionsbildung können die Mechanismen erhellen, die zu einer vom modifizierten 'Priority-of-access' Modell abweichenden Verteilung der Fortpflanzungstätigkeit führen.

Die fehlende Übereinstimmung der Daten mit dem ursprünglichen 'Priority-of-access' Modell kann nicht auf eine ausgeprägtere Selektivität der ranghohen Männchen zurückgeführt werden. Die ranghohen Männchen hatten einzig dahingehend einen Vorteil, dass sie bevorzugt frühmorgens kopulierten. Dies rührt daher, dass sich Consort-Paare meist während der Nacht oder in den frühen Morgenstunden in den Schlafbäumen bilden. Dort haben einzelne, starke Männchen einen Vorteil gegenüber Koalitionen von rangtiefen Männchen. Diese wiederum sind später am Tage erfolgreicher, wenn die auseinandersetzungen um Weibchen am Boden ausgetragen werden. 